عرض الباليه الكلاسيكي هو منظومة من الصور الكوريوجرافية المتر ابطة في سباق درامي راقص، وهو فن من الفنون المسرحبة التي تتكون من عناصر فنية متعددة؛ الرقص، الموسيقي، الأزياء و المناظر المسرحية، كما استعان بفن البانتوميم. وفي الباليه الكلاسيكي يتم الإلتزام بالقواعد

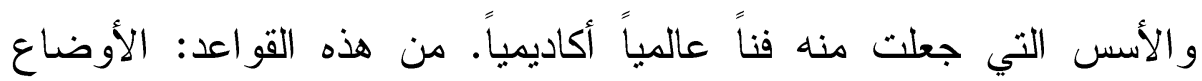

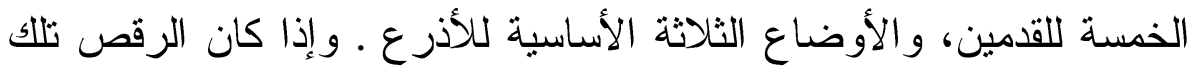

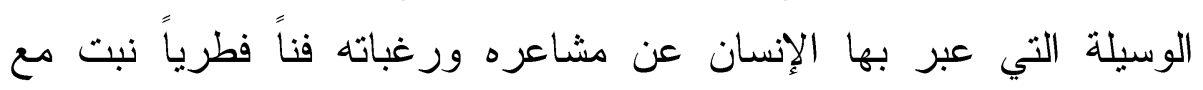
الإنسان في الطبيعية التي يحيا وسطها، فإن فن الباليه قد إثنق من إحتفالات الإنات

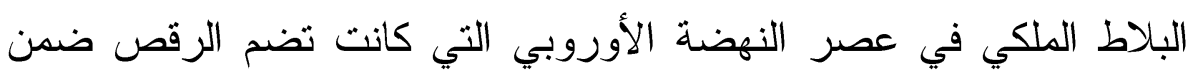
فاعليتها للربط بين فقرات الحفل المتتوعة.

\title{
إثكالية البحث:
}

من مشاهدات الباحثة للعديد من عروض الباليه أثناء الدراسة في

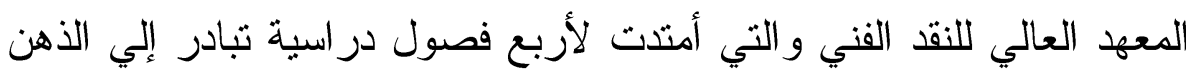

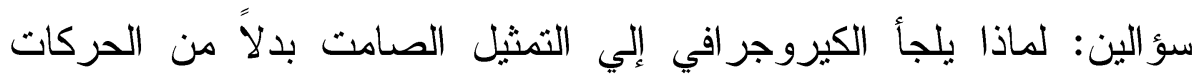

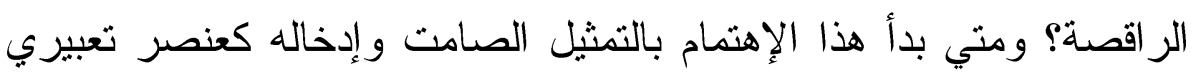
في عروض الباليه؟

\section{الكثماث المفتاحية}

Mimique إيماء إيماء Pantomime إيماء Mime بالفرنسية: مترادفات للتمثيل الصامت. وقد إختارت الباحثة لفظ 
الملانتوهايه هين مروض المباليه الكلاسيخيى

البانتومايم (بانتوميموس) كمصطلح يعبر عن التمثيل الصامت في

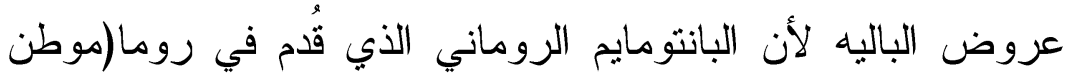

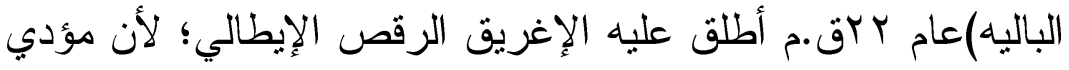

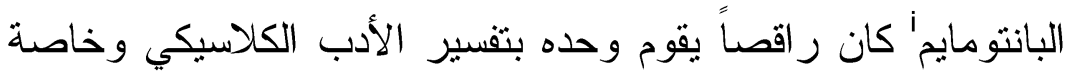

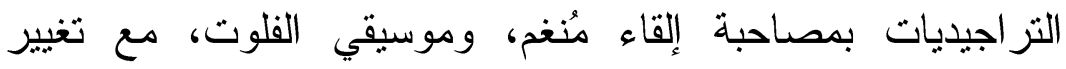

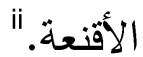

r- الباليه: كلمة باليه Ballet هي كلمة إيطالية مشتقة من كلمة

Ballare

r- الكيروجرافي Choregraphie -Choreography هو مصمم ومخرج عرض الباليه. وتطلق أيضاً علي مصمم الحركات الراقصة بعروض الدراما المسرحية الأخري. ع - Ballerine -Ballerina تطلق علي الراقصة الأولي التي نقوم

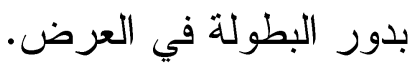
Solo -0 تطلق علي الراقصة المنفردة، أو الر اقص المنفرد. צremiereas de deux Pas de trios -ᄉ رقصة ثلاثية. Corps de ballet -9 المجموعة أو هيئة الباليه. أولاً: التمثيل الصامت(مايم- بانتومايم): في البدء وجدت كلمة mimos (ميموس) اليونانية تعني الثخص الذي يغني ويرقص ويخلق الإيهام. والكلمة أيضاً تعني العمل الذي يؤديه 
الفنان ( وهو شكل من أشكال المسرحية الكوميدية الشعبية وفقاً لدليل

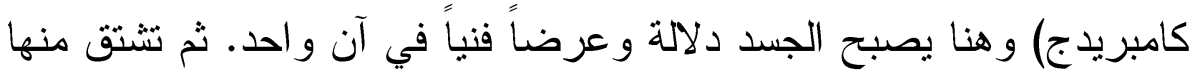
كلمة mimesis و الفعل mimesthai، وقد يعود أصلها - كما قال العالم الألماني شولتز Schulze إلي Maya أي الوهم الأوّلي الذي يخلق في

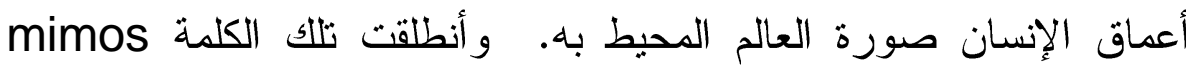
من أتيكا Attique أو عند الأيونيين loniens لتغزو العالم اليوناني. iv الإنيان أما البانتومايم Pantomime (عند الإغريق) فيشير إلي عروض مبنية علي القصص الخرافية المحشوة بأغان شعبية وكوميدية وحركات حسية مثيرة في كثير من الأحيان، كما يشارك الجمهور في فاعليتها بشكل حقيقي. في القرن الخامس ق.م كان المايم يتراوح بين مسرحيات قصيرة

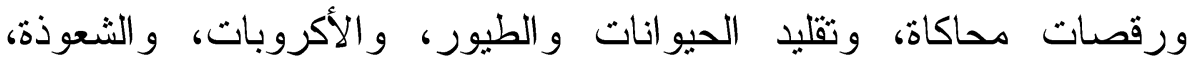

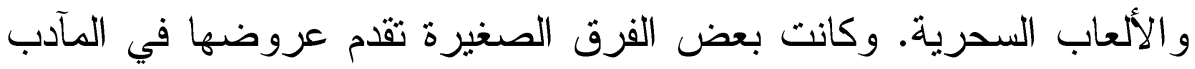
و المناسبات الأخري. وفنانو المايم هم أول المحترفين الذين قدموا عروض الهرف تسلية وكانو ا أول من سمح للنساء بالإثتر الك معهم. كانت هذه المسرحيات تقوم علي المحاكاة الساخرة Parody من الشخصيات الأسطورية، ثم أصبحت عبارة عن أسكتشات عن الحياة اليومية المعاصرة. وقد وُجد نوعان من عروض المايم: شعبي وأدبي. المايم الشعبي: عبارة عن عروض كوميدية فظة تعتمد علي الحركة والإيماءة،

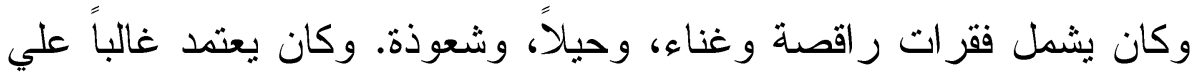

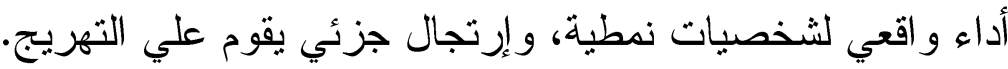


وكان هيروداس Herodas - أحد فناني المايم الشعبي - يحول

صوراً موجزة للحباة اليومية مقدماً شخصيات مثل: ناظر المدرسة، الطبيب النصاب.... و غيرها كثخصيات ثابتة في عروضه.

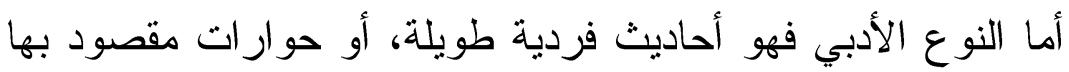

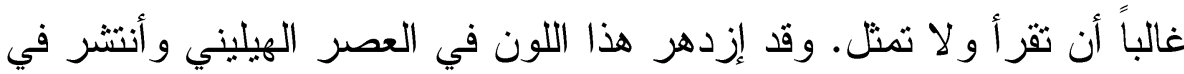
شرق البحر المتوسط، وظهرت مدرسة لكتاب المايم الأدبي في الإسكندرية وجنوب إيطاليا. وقد أثتهر المايم الروماني بوجود المومسات بين أعضاء

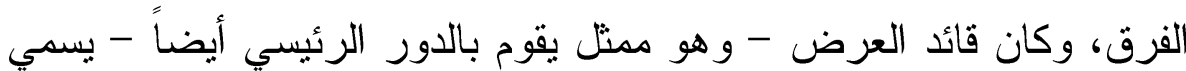
آرسيميوس Archemimus نسبة إلي Archemima ذلك اللفظ الذي فئي أطلق علي تلكك العروض الميمية التي إثتملت بدورها الشخصيات الكوميدية النمطية مثل شخصيتا الغبي Stupdus، وصانع الأوجه Sanio. في عهد يوليوس قيصر Gaius Julius Caesar (• (1-2؛ ؛ق.م) أخذ المايم شكلاً أدبياً علي يد ديسيموس لابيريوس Decimus Labirius، وكان يقدم في الإستر احة وبعد المسرحية التز اجيدية.

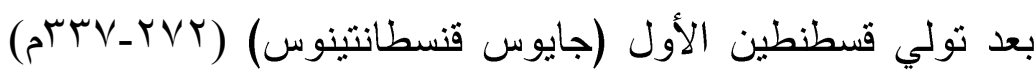

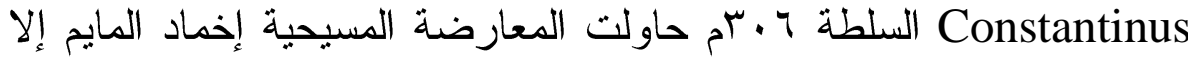
أنه بقي حتي العصور الوسطي في شكل المغنبين المتجولين Jongleurs

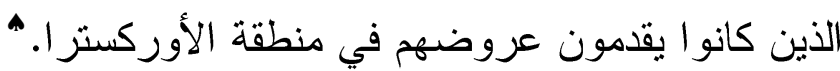
ولكن بعد تفوق المايم علي التراجيديا في الثعبية أصبحوا يعرضون

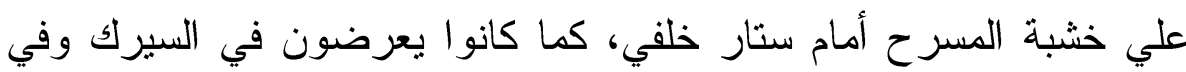

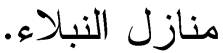


الملانتوهايه هين مروض المباليه الكلاسيخيى

وقد عرف البانتومايم الروماني بأسم فابيو لا سالتيكا Fabula Salatica ما، بمصاحبة موسيقي وعناء فردي أو كورس، فيما يشبه الرقص فئرة الحديث(كأسلوب فني تعبيري). أما المؤدي في البانتومايم " فكان يرتدي قناع فئاعاً لكل شخصبة يمتلها، وكان يغير قناعه خلال فترة التوقف الكورالي(توقف الغناء فردي أو جماعي)، وكان يستخدم خطوات و أوضاع ووقفات جسم

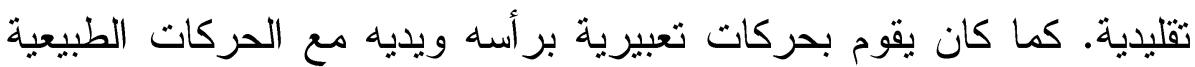
للجسم متل: الإنحناء، و الدوران، و القفزات ولذلك كان يتدرب بلا توقف وكان يتتاول وجبات خاصة ليس بها دسم وكان محبوباً دائماً من الطبقات الر اقية"ا. Saint حاربت الكنيسة البانتومايم في عهر القديس أوغسطين Augustine

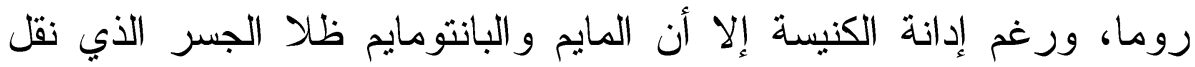
تقاليد التمثيل المحترف - وخاصة التمثيل الصامت - إلي العصور الوسطي. و إنتقلت تقاليد التمثيل الصامت إلي فرق الكوميديا دي لارتي" Commedia dell'arte وأمتزج اللفظ بالحركات الجسدية في عروضهر. وفي القرن السادس الميلادي ظهرت العروض التي تمزج بين الرقص و التمثيل الصامت. وقد جاءت أول فرقة إيطالية إلي فرنسا وكان قادرة علي جعل جمهورها الباريسي يفهها دون صعوبة بفضل إيمائها البار ع" وجدير بالذكر أن فنون النعبير الصامت كانت طوق النجاة لكثير من الفنانين(غير الثرعيين) في القرن الثامن عشر، حيث منعوا من إستخدام 
الحوار في عروضهم فلجأوا غلي تطور الوسائل التعبيرية الأخري؛ فكان Pierre الجسد هو مادة التعبير وحامل الرسالة. ومن هؤلاء بيير آلار Alard

وقد أصبحت الإيماءة مبداً هاماً في نظرية التمثيل في أواخر القرن Johan Jacob Engel الثامن عشر حين أقترح يوهان جاكوب إنجل

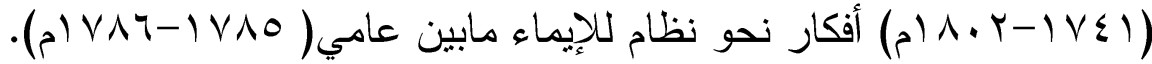
منذ او ائل القرن التاسع عشر تطورت عروض التمثيل الصامت لتجد

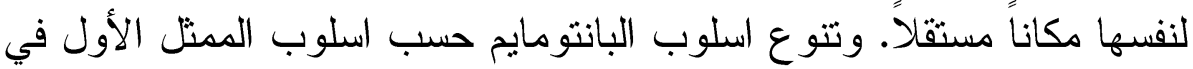
Charles Francois Mazurierالفرقة، مثل شارل فرانسوا مازورييه

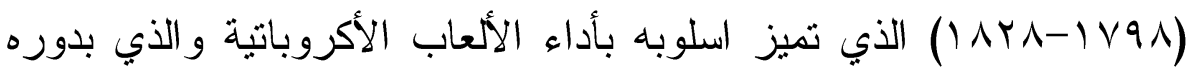

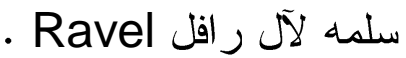
في القرن العشرين ظهر الفيلم الصامت الذي أكد العلاقة بين التمثيل الهزلي و الكوميديا اللفظية. و والمسرح الراقص الذي ربط من جديد بين التثثيل الصامت و الرقص علي يد إزادورا دانكان Isadora Dancan ، Martha Graham (م) (

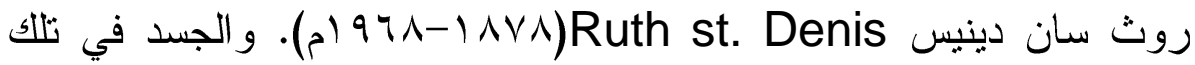
العروض يلعب دوراً بالغ الأهمية حيث تتجسد القصص و الحكايات و الحبكات بواسطة لغة الجسد. وأصبحت الإيماءة تعبير ملموس لا يعني بإعادة إنتاج

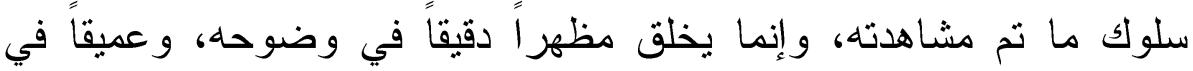
دلالته وقر اءتها. ثانيا: فن الباليه: نشأته وتاريخه 
كانت إحتفالات البلاط الملكي في عصر النهضة نضم العديد من

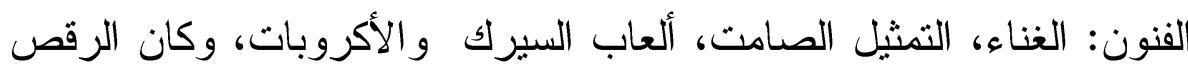
يربط بين فقرات الحفل المتتوعة، وكان يؤدي بواسطة النبلاء وعلية القوم. ويعد أول عرض رقص(باليه) منفصل عن تلك الفنون هو ذلك العرض الذئي

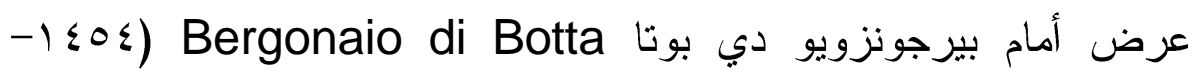

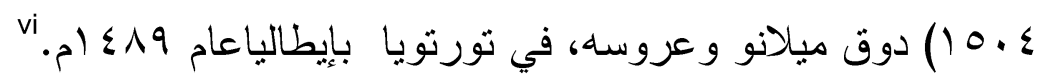

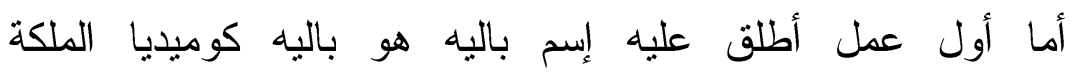
Comeque de la Reine كاترين دي ميديتثي Catherine De Medici زوجة الملك هنري الثاني

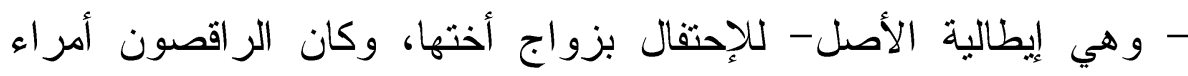

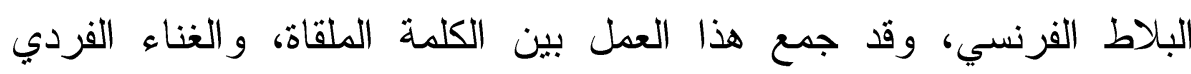

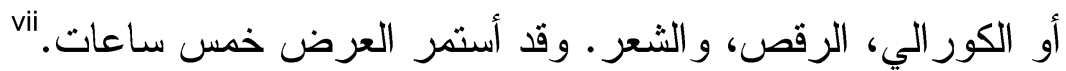
ومع تأسيس أول أكاديمية للرقص؛ الأكاديمية الملكية للموسيقي و الرقص Academy Royal de Musique et de Dance في باريس سنة الج4 (ام، أصبح الباليه فناً قائماً بذاته، وذا أسس ونظريات. وقد

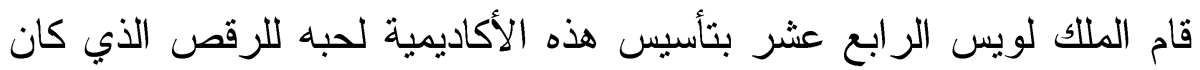

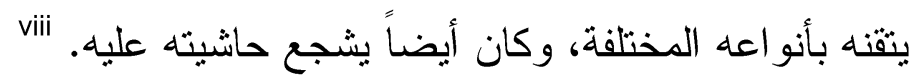

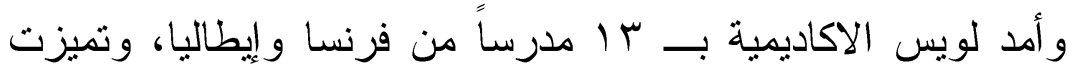
رقصاتها بحركات ناعمة ورشيقة ولم تعتمد علي البر اعة الفائقة.

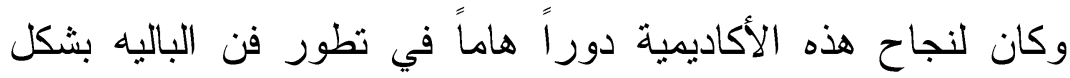

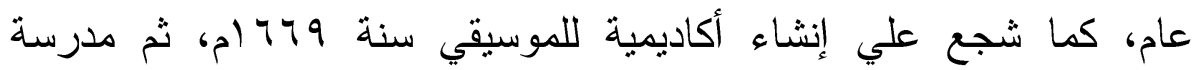


للرقص سنة rVT ام لتدريب الر اقصين المحترفين، ثم تراجعت خصوصية

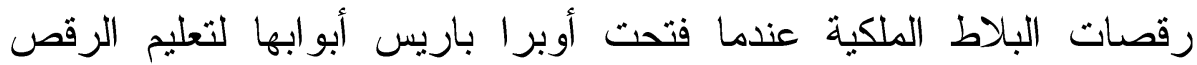

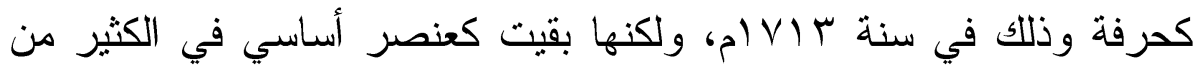
الباليهات الكلاسيكية حيث وظفت هذه الرقصات في أعمال مثل: باليه بحيرة البجع الذي يتضمن رقصة الفالس، وباليه كسارة البندق، ودون كيشوت الذان يتضمان رقصة المنويت. نوالي إنشاء الأكاديميات و المعاهد الفنية المتخصصة في الباليه

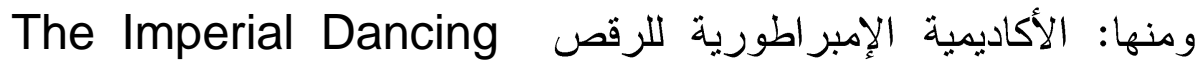
Academy

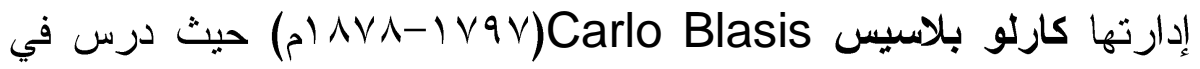
عهده أبرع الراقصين الذين أصبحوا أساتذة فيما بعد مثل أنريكو تشيكيتي Enrico Cecchetti

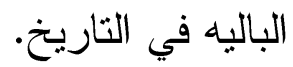

قدم بلاسيس لدارسي ومعلمي الباليه كتابين يحتويا أسس الباليه

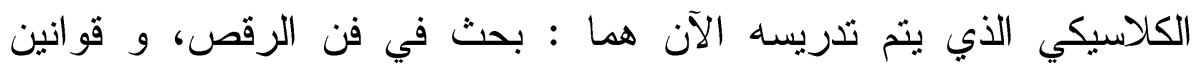

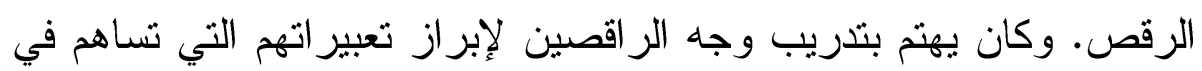
رسم ملامح الثخصية ومشاعر ها.

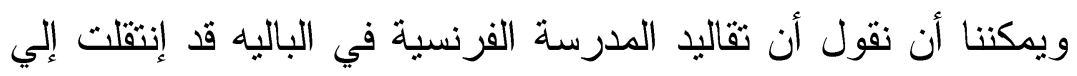

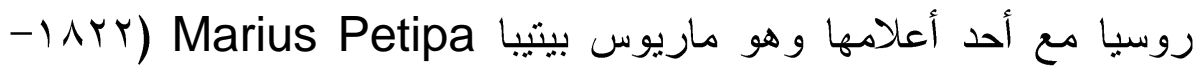

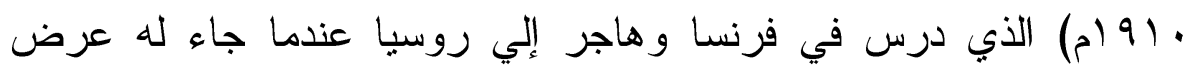


ليشغل منصب الراقص الأول Premiere في شعبة سان بطرسبرج من

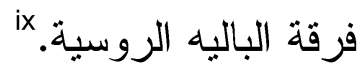

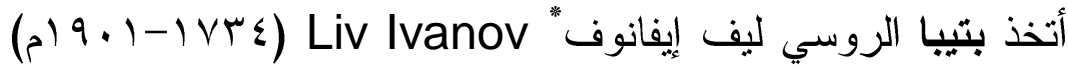

كمساعداً له في العديد من الإعمال. وقد إرتقي بيتيبا بفن الباليه وأهتم بدور

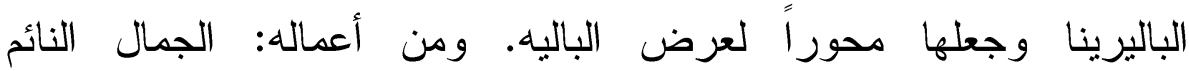
Daimonda Sleeping beauty ، دون كيشوت Don Quichatte. وفي القرنين الثامن عشر والثاسع عشر ظهرت على خشبة المسرح

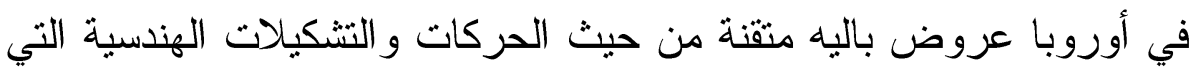

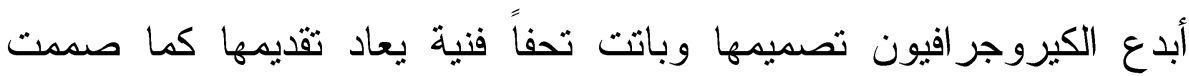

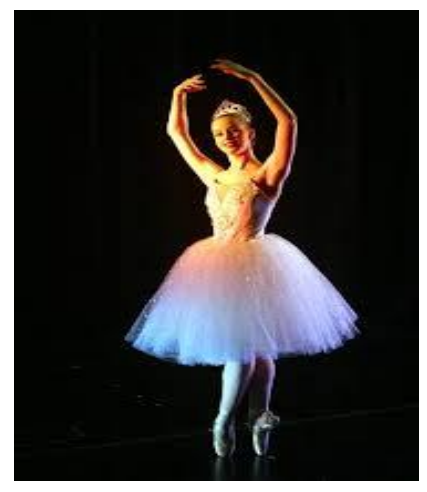

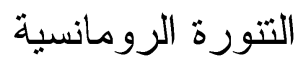

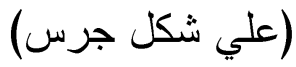

$$
\text { لأول مرة، أو برؤي فنية جديدة. }
$$

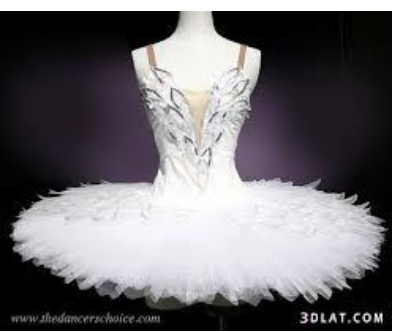

tutu التنورة الكلاسيكية

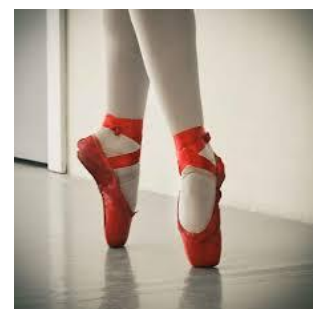

حذاء الباليه pointes

\section{LETTRES} PATENTES

DV ROY.

POVR LEEABLYSSEAR NVT del Academie Royale de Danfe en la ville de Paris.

Verifices en Parlement le zo. Mars r 66 :

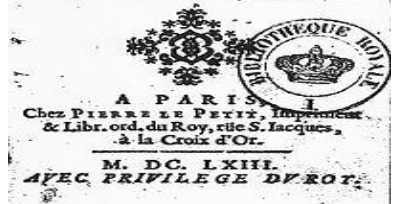

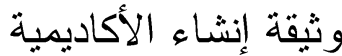

الملكية للموسيقي

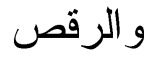


اللمانتومايه هيه مروض المباليه الحلاسيخيه
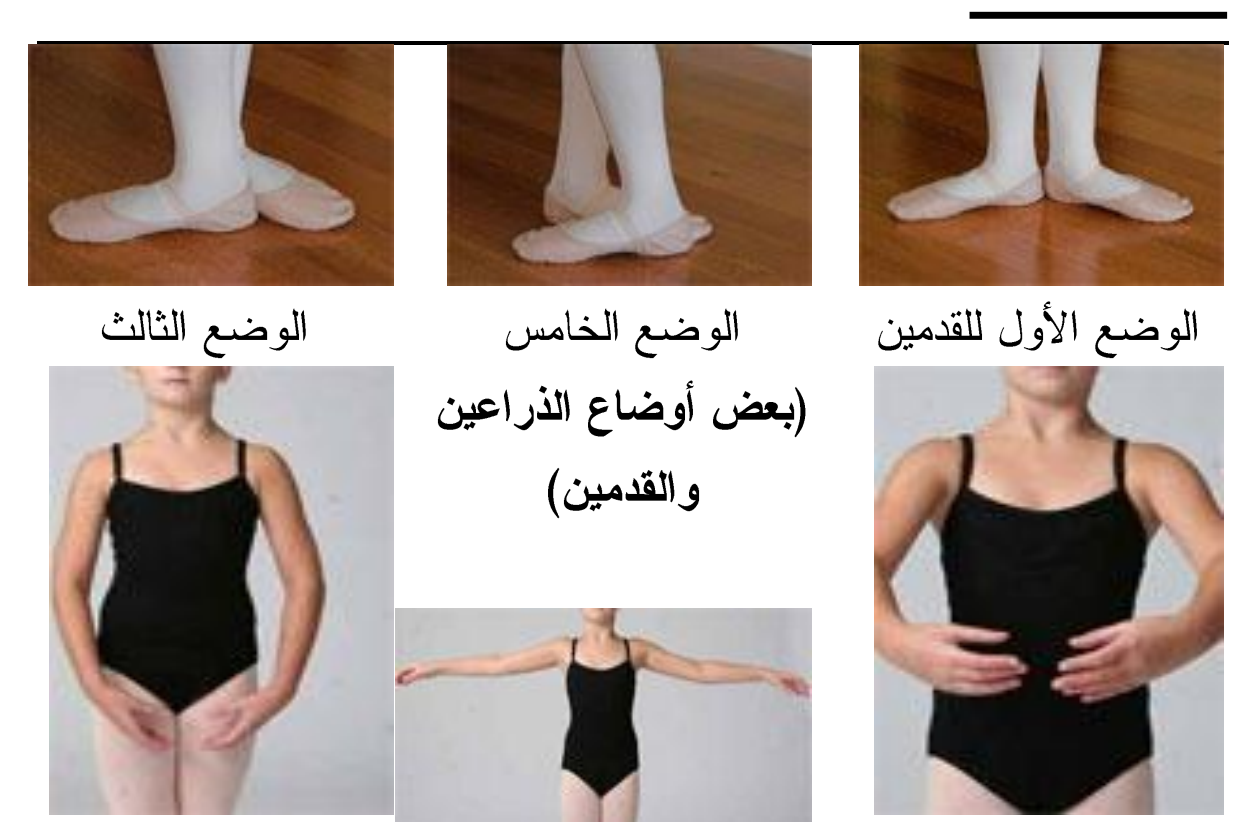

$$
\text { الوضع الخامس }
$$
(بعض أوضاع الأراعين

و القدمين)

$$
\text { الوضع الأول }
$$

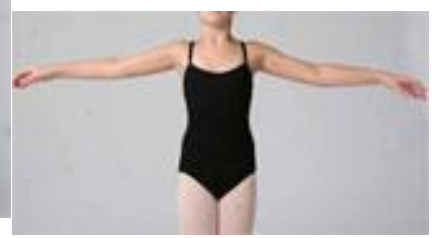

$$
\text { الوضع الثالث }
$$

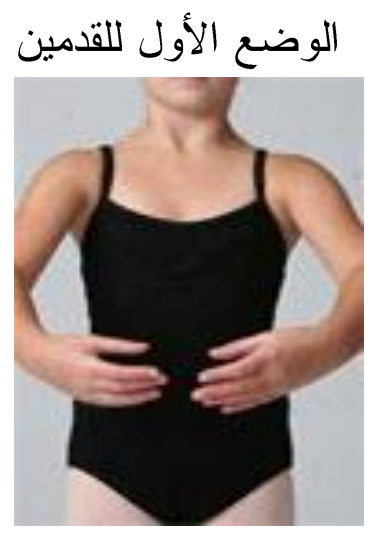

الوضنع الثاني

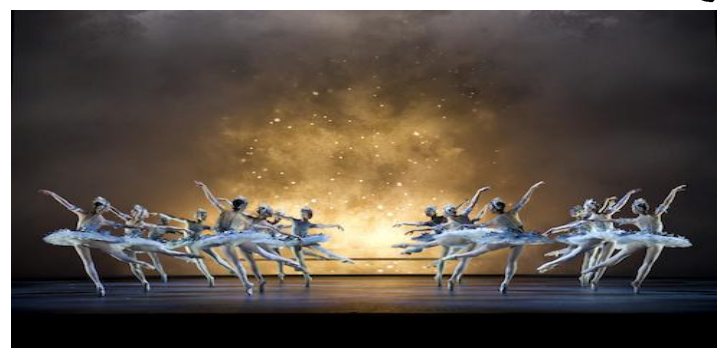

رقصة مجموعة الباليه Corps de ballet

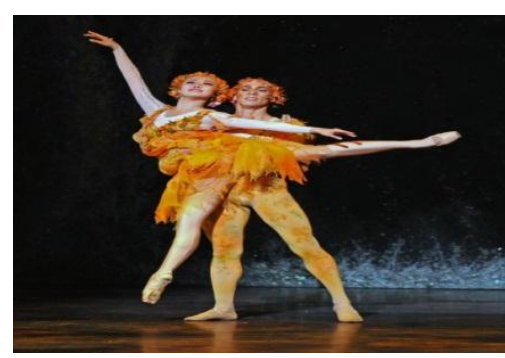

Pas de رقصة مزدوجة deux (أحد عروض باليه سندريلا)

\section{ثالثاً: العلاقة بين البانتومايم و الرقص}

بدأ الرقص و البانتومايم مع البدايات الأول لمحاولة الإنسان التعبير

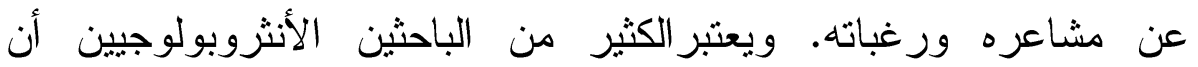


رقصات الصيد التي تحاكي طريقة صيد الحيوانات هي أولي أثكال المحاكاة

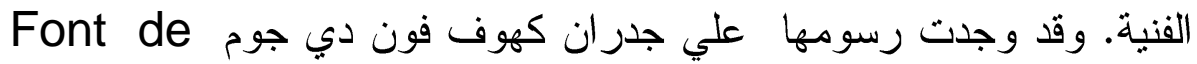
في حوض نهر دردوني Dordone جنوب فرنسا، أما في إقليم

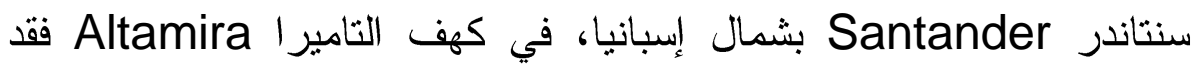
عثر علي تصوير يمثل مشهداً تمثيلياً بين الإنسان وتلك الوحوش (كالثيران

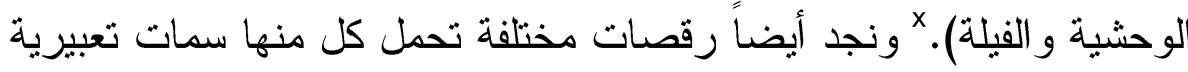
لموقف من الحياة أو رغبة يريد الإنسان أن يحصل عليها مثل رقصات:

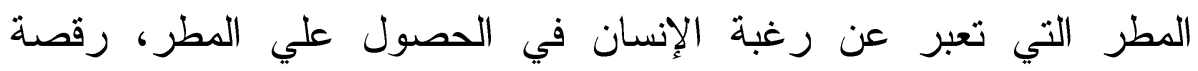
الإحتفال بالخصب و الحصاد التي نجدها عند قدماء المصريين للإحتفال بالإله أوزيريس، ومثيلتها عند الإغريق للإحتفال بالإله ديونيسيوس، ورقصة إحتفالات البلوغ للفتيه في قبيلة ما، ورقصات الحرب عند الثُعوب القديمة. في القرن السادس عشر كان الرقص ضرورة إجتماعية في فرنسا،

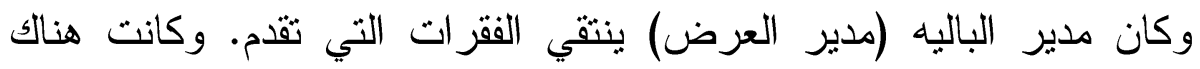

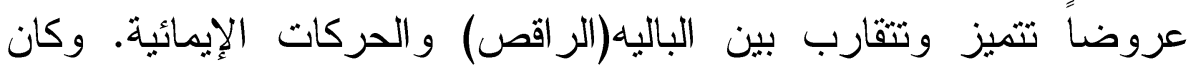

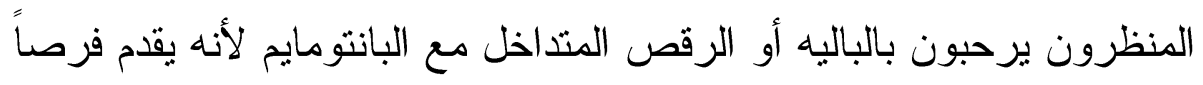

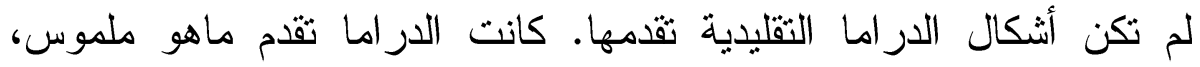

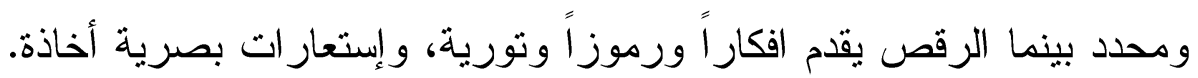

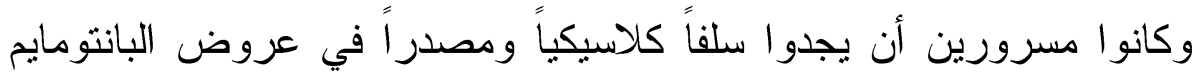
في العالم القديم.

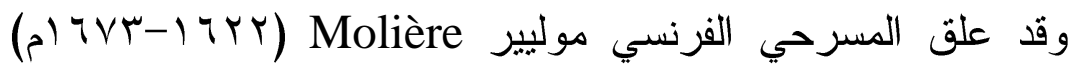
علي راقص يدعي أندريه Andre في عرض باليه "الهحبين الباهرين" بأنه 
حقاً ممثل؛ حيث إنه بحركات يديه وجسده وجه أنظار الجميع لما يسمي بالفن الصامت. xi

تقول أوديت أصلان الباحثة المسرحية: "إن فن التمثيل الإيمائي أكثر در امية من الرقص وعندما يتحرر يتجه إلي الرقص، في حين يتجه الراقص

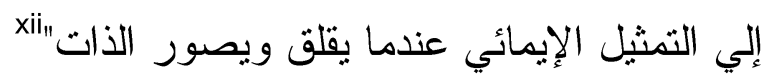

إهتم سيرجي ليفار وهو ناقد متخصص في فن الباليه بالتمثيل الصامت الذي يؤديه الر اقصون، وقسم الإيماءات إلي ثثلاثة أنواع: ا ـ الإشارة الخالية من الغرض: تعتبر تمهيد للحدث. Y. الإشارة النفعية: هي حركات آلية لها مدلولها وترتبط بالعمل مثل: حركة اليد وهي تكتب، حركة الفلاح وهو يحصد بالمنجل، الترزي وهو يعمل، حركات شارلي شابلن في الأفلام الصامتة. r. الإشارة المجازية: إشارة لها مدلولها الذي إكتسبته من السياق الإجتماعي التي نبتت فيه، مثل الإشارات المتعارف عليها بين الصم و البكم والتي تمثل في مجملها حروفاً هجائية لا بدركها غير المجموعة التي

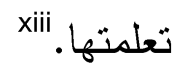

\section{رابعاً: التأصيل للباتتومايم في عرض الباليه}

\section{كان جان جورج نوفير IVYV) Jean Georges Noverre} • 11) الر اقص ومصمم الرقص الفرنسي، هو أول من دعا إلي العديد من الإصلاحات في مجال الباليه منها: الإهتمام بالتمثيل الصامت/البانتومايم، و التأكيد علي الإقتراب من الواقعية و الطبيعية. ويعتبرنوفير المصلح الأساسي 
فبفضل مجهوداته تحول الباليه إلي فن مستقل بذاته. وقد انتج أول باليه عام

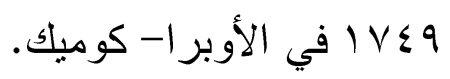

ألف نوفير أهم كتاب لفن الباليه ظهر في القرن الثامن عشر وهو:

رسائل في الرقص و الباليه Letters on Dancing and Ballet رد فيه علي التساؤلات المرتبطة بالرقص والباليه. كما قام بتقسيم العناصر الحركية الموجودة بمنهج الباليه الكلاسيك إلي سبع مجموعات منها: مجموعة الثني، المد، التزحلق، الإنطلاق، الإرتفاع، الوثب... قسم نوفير الرقص إلي نوعين: تكنيكي وواقعي صامت، ويقول في الإنهاع إحدي رسائله: "يتحدد الرقص بالتكنيك وبالحركات الميكانيكية للأرجل وبذلك يمكن النظر إليه كمهنة يتوقف نجاحها علي المهارات، وعلي السهولة، و القوة، والرشاقة في أداء الفقرات، أما عندما يتخلل هذه الحركات الميكانيكية

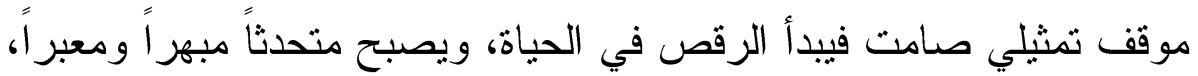
ويستحق أن يصبح ضمن الفنون التعبيرية الأخري"

\section{نوفير وجاريك:}

عندما ذهب نوفير إلي لندن عام V\& V ام، إلتقي بديفيد جاريك* (مVYq-IVIV) David Garrick دوراً هاماً ظهر تأثيره على جميع نواحي وجوانب المهنة المسرحية وخاصة التشثل في إنجلترا- خلال القرن الثامن عشر الميلادي؛ حيث كان

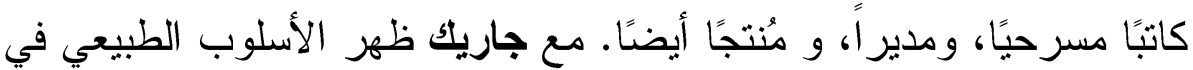

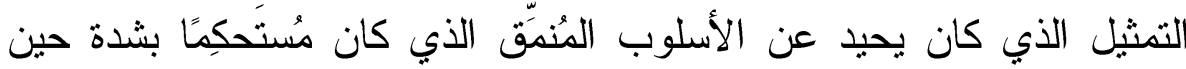


ظهر جاريك لأول مرة على الساحة الفنية. إنعكس إسلوبه علي العديد من المثنلين المسرحيين الإنجليز بشكل كبير على أساليب تمثيلهم. ويمكن أن نلخص أسلوب جاريك في ثلاثة عناصرهي: الطبيعية و الديناميكية، و الصدق؛ كان جاريك يؤدي أدواره بطبيعية بالغة لا تحدث في في تلانه

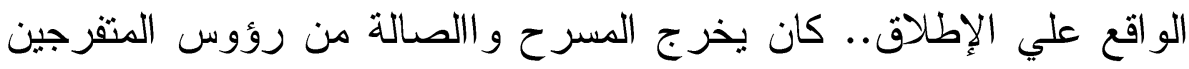
تماماً، ويكون بالفعل بالنسبة لهم ولنفسه، ما يبدو هو بالنسبة لممثل آخر (أي

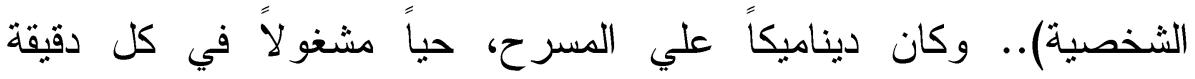
بالمشهد.. وكان يتابع المشهد دون مبالاة بتلفظ الحديث، بل بالتعبير الفوري

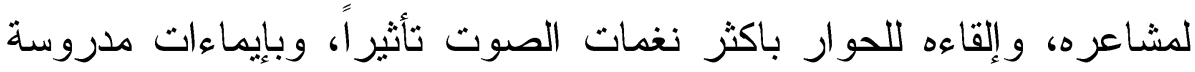
ومعدة جيداً، لا تتسم بالتلكف بل تتنهج الطبيعية في الأداء.

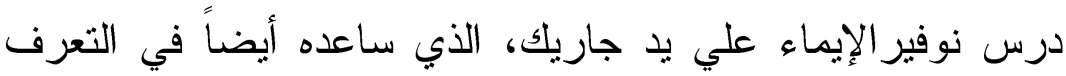
علي المسرح وفهم شكسبير، كما تتبع أعمال الفلاسفة وأراءهم عن المسرح الر اقص، ودرس المسرح القديم والرسائل القديمة التي تتعلق بفن الرقص

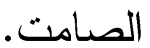

ذكر نوفير في العديد من الأبحاث مدي أهمية وحيوية ملامح الوجه

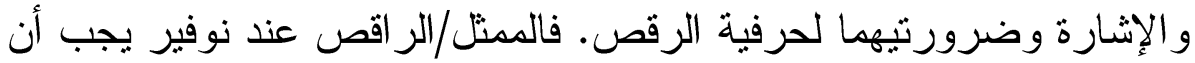
يتقن الفن الصامت وأداء الإثارة الطبيعية لأن - بالنسبة لنوفير - الإشارة المصتتعة لا توحي بالإرتياح النفسي.

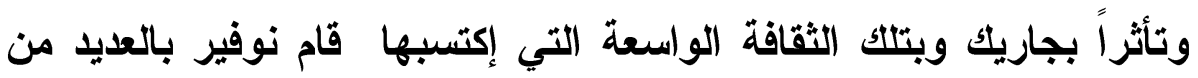
الإصلاحات في مجال الباليه ومنها:- 
1. تحرير الرقص من الأقنعة والباروكات والملابس الرسمية ذات الزينات

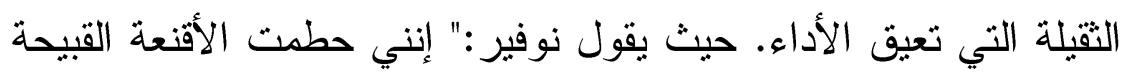

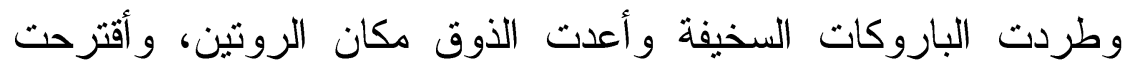
الصدق والنشاط والحيوية في الحركة علي المسرح كذلك التعبير الر اقص"

r. طالب بفصل عرض الباليه عن الأوبرا حيث كان الرقص مُتضمن في

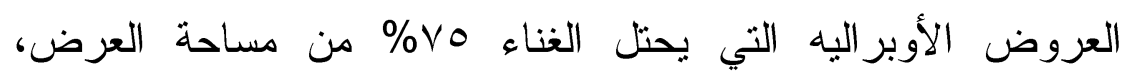
و الرقص OY\% فقط.

r. دعا إلي وحدة تصميم القصة، و الإلنزام بالتتابع المنطقي من المقدمة إلي

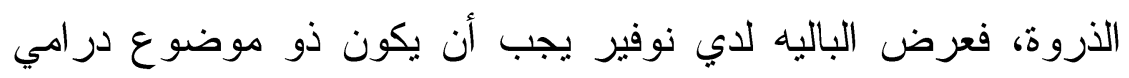

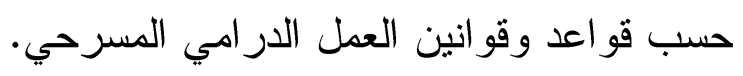

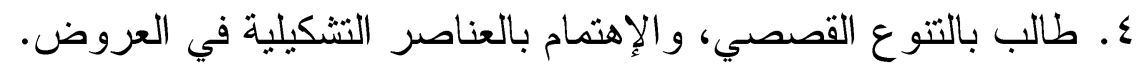

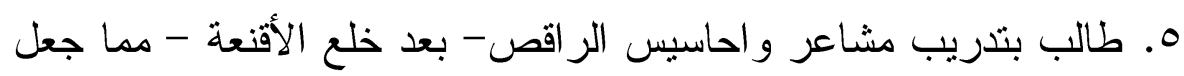

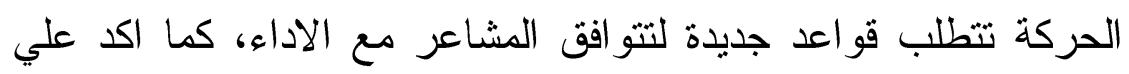
إن تتبع الحركة الإيقاع الزمني والإرتفاع الموسيقي. فأصبح فن الباليه

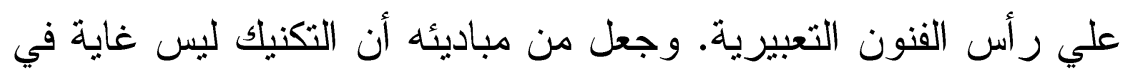
حد ذاته و إنما وسيلة إعدادية ضرورية للتعبير • و علي ذلك بلكئل بالبانتومايم-

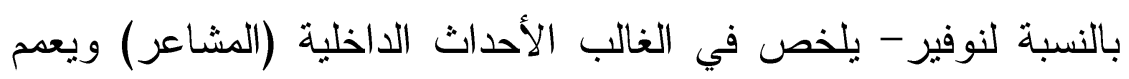
الرقص الفكرة الظاهرة له، الأول هو الذي يضع روح البالب البهاليه والثاني 
I. كف عن إستخدام هيئة الباليه كخلفية يؤدي أمامها الر اقصون الرئيسيون متتابعات الرقص التقلبدي، وجعلهم يؤدون إيماءات وحركات أقرب للو اقع حتي يحقق مصداقية المشهد. من كتابه رسائل عن الرقص والباليه يقول: لم تكن رسائلي سوي الحجر الأول للصرح الذي كنت أرغب في إقامته لهذا الشكل من الرقص المعبر الذي أسماه الإغريق بانتوميم ومعروف جيداً لأي مدي كان فنانو المايم القدماء بارعين في فن التأثثر في الجمهور بالإيماة.. إن الإيماءة تثرك

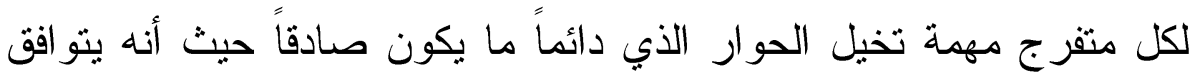
دائماً مع الإنفعالات المتلقاه. وقد قادني هذا التأمل إلي الفحص بإنباه دقيق لكل ما يقع في كل من عرض باليه البانتوميم وعرض المسرحية(بإفتر اض أن لهما ميزة متساوية في مجالهما) كان الأمر يبدو لي أنه في البانتوميم يكون التأثير عاماً أكثز وموحداً أكثر ولوأمكنني القول أن ذلك أكثر في التناغم مع الأحاسيس الكلية التي يثير ها العرض. قدم نوفير نصائح للممثلين الر اقصين أهمها:

- في المشهد الصامت يجب أن تتم تدريبات مستمرة حتي نصل إلي لحظة الصدق التي هي وليدة الإحساس. ويأتي الصدق من تتطابق الإيماءات بالإحساس. - إكتسب كل المعرفة التي بإمكانك عن المسألة التي في يدك سيوفر للك خيالك الممتليء بالصورة التي تزغب في تمثيلها، الأشكال المناسبة، و الخطوات و الإيماءات عندئذ ستتو هج تشكيلاتك بالنار و القوة لن يمكنها

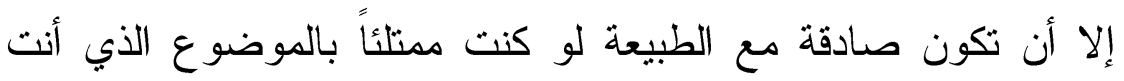


الملانتوهايه هين مروض المباليه الكلاسيخيى

بصدده.. كل حركة ستكون معبرة، كل وضع جسدي سيصف موقفا معيناً وكل إيماءة ستكثف عن فكرة وكل لمحة ستنقل إحساساً جديداً،

$$
\text { كل شيء سيكون آسراً. }
$$

خامساً: تحليل العينات البحثبة: سئة

تختلف الحركات التي تؤديها الشخصية منفردة، أو مع الشخصيات الأخري حسب الموضوع، و الزمان و المكان، و الموقف الدرامي. ويعمل المصمم علي إبراز الثخصية الرئيسية عن طريق علاقتها بالمجموعة corps de ballet المجموعة بأداء حركات مكملة له في الخلفية وتكون بمثابة إطار للبطل أو البطلة مما يساعد علي تكوين تابلوهات تشكيلية. ومن الكيروجرافيين من يجعل عمل المجموعة بأسلوب التمثيل الصامت في الخلفية فيضفي عليها

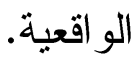

وفي بعض الأحيان تبدو لغة الرقص عاجزة عن التعبير عن المضمون الدرامي أو الفلسفي لمشهد ما مثل: مونولوج( أكون أو لا أكون) Shakespeare علي لسان شخصية هاملت، في مسرحية ويليام شيكسبير

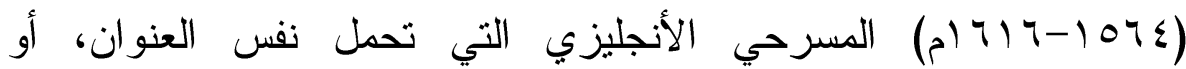
Leo Tolstoy مونولوج أنا كارنينا في رواية الروسي ليو تولستوي

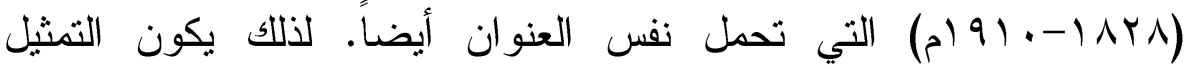
الصامت فاعلاً في منل هذه المواقف كوسيلة للتعبير عن مضمونها. وقد يعتمد البانتومايم أيضاً كعنصر أساسي لتجسيد الشخصية الكومبدية في عروض هلي البالبه الكلاسيكي، مثل شخصية سان شوبانز ا في باليه دون كيشوت، زوجة 
الملانتوهايه هين مروض المباليه الكلاسيخيى

الأب وأبنتيها في باليه سندريلا، وكذللك الأم، والأمراء في باليه جيزيل،

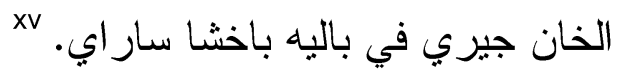

وهناك العديد من الباليهات التي شاهدتها الباحثة أثناء الفترة باتئان

المخصصة للبحث (منها عطيل، جيزيل، فتاة منحررة، سبارتاكوس) ولكنها إكتفت ببعض النماذج كدليل علي ماتوصلت إليه الباحثة في رحلة الإجابة عن فئن

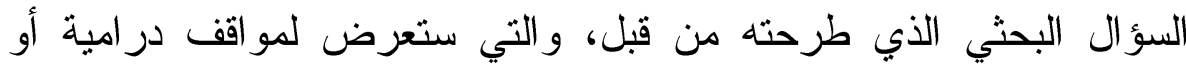

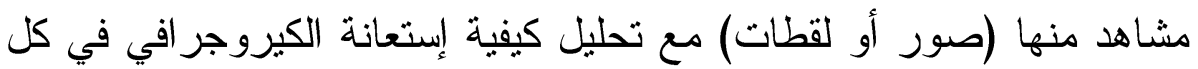
باليه بالبانتومايم ولماذا؟ وقد تم إختيار هذه النماذج لتتوع مصادر ها والتي لتاني

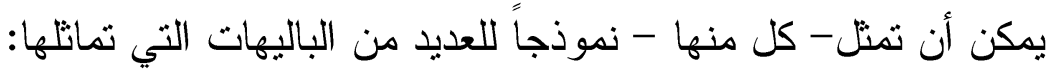

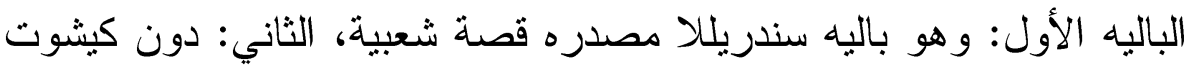

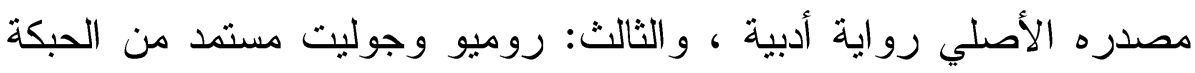
الشيكسبيرية للحكاية الشهيرة التي وضعها في مسرحيته التي تحمل نفس العنوان، و الرابع: نافورة باخشاساري: مأخوذ عن قصيدة لأكسندر بوشكين

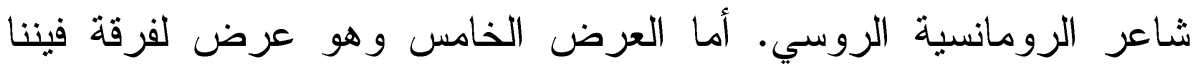

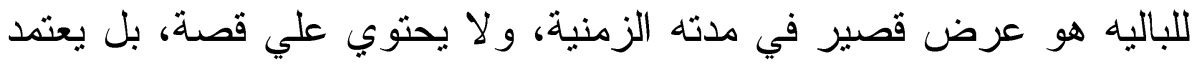

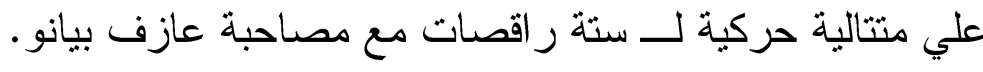

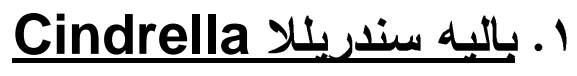

قصة هذا الباليه مشهورة. وهي قصة فتاة/سندريلا تعيش مع زوجة

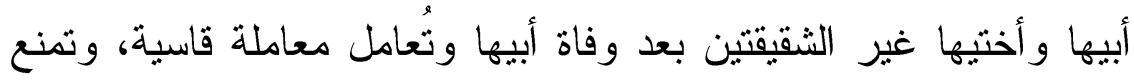
من الذهاب إلي حفل الامير، ثم تاتي لها الساحرة الطيبة وتساعدها علي وناي الظهور بالمظهر اللائق للحفل..تترك سندريلا الحفل في الموعد الذي لاني 
حددته لها الساحرة الطيبة من قبل، فتفقد إحدي زوجي حذائها. ويقع الحذاء في يد الأمير الذي برسل رسوله في جولة في البلدة لكل بعثر علي صاحبة الحذاء التي ملكت عليه قلبه. وتثوالي الأحداث بشكل كومبدي حتي يجد الأمير فناته وتصبح هي أميرة أيضاً

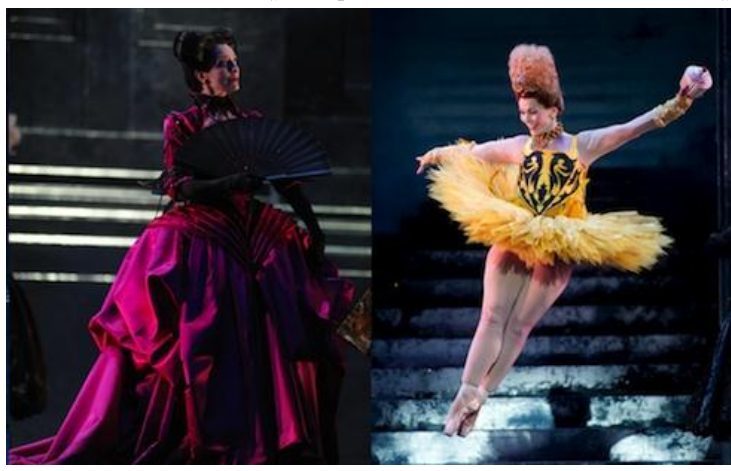

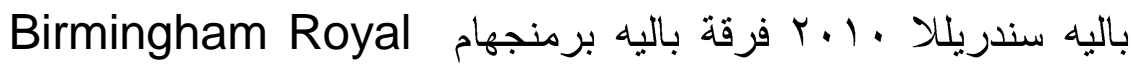

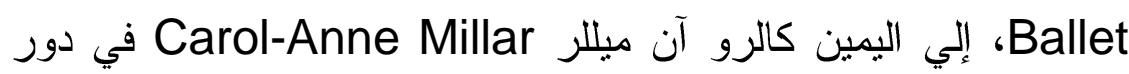
الساحرة الطيبة، إلي اليسار : ماريون تايت في دور زوجة الأب Marion Tait ويتضح من الملابس التي صممت للشخصيتين ما يؤكد طريقة التعبير الحركي الذي إختاره الكيوروجرافي ديفيد بينتلي David Bintley. 
اللمانتومايه فيه مروض المباليه الكلاسيخيه

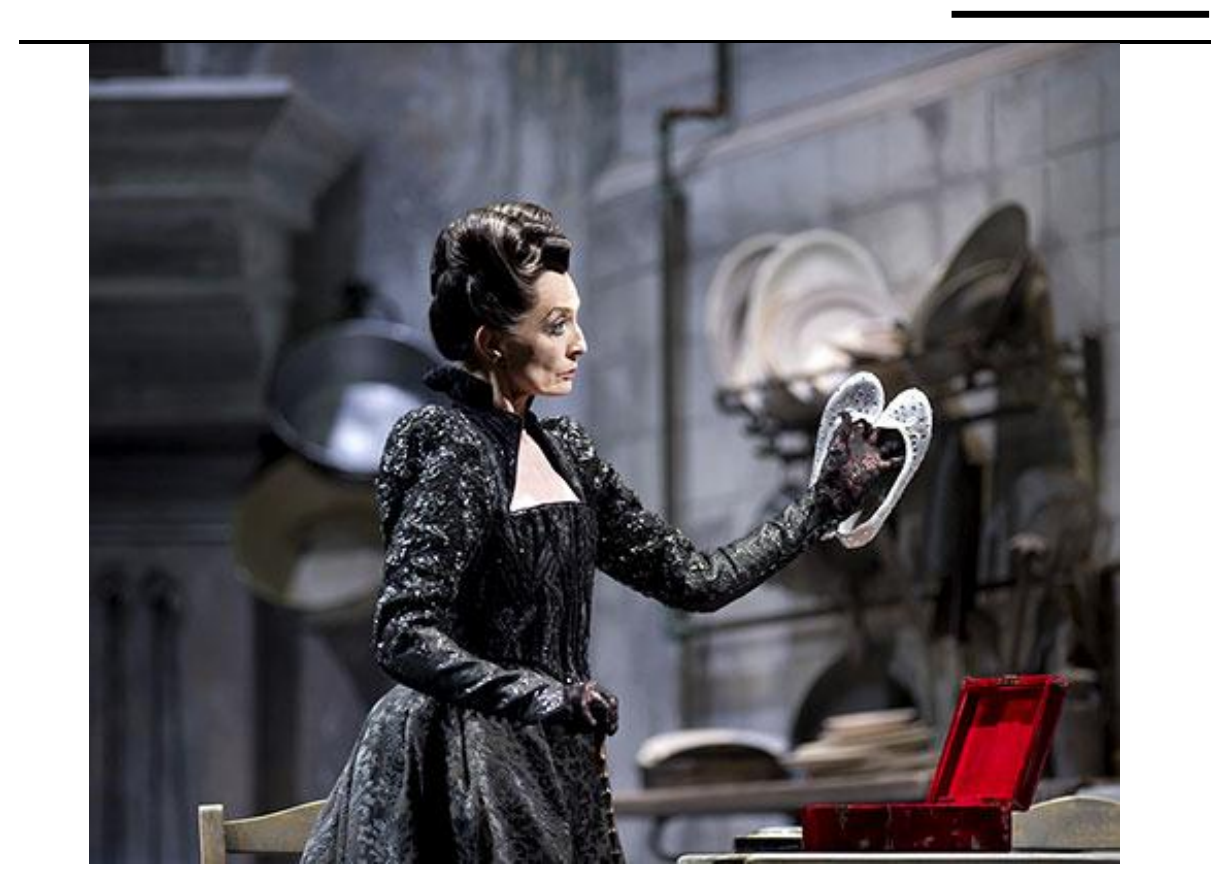

اللحظة التي فتحت فيها زوجة الأب علبة سندريلال ووجدت حذاء أمها الغالي وتلك النظرة الغريبة و التعبير بالعينين عن إنبهار ها به... في تلك اللحظات يتقوف التمثيل الصامت في التعبير عن الإنفعالات والأحاسيس للشخصبة. 


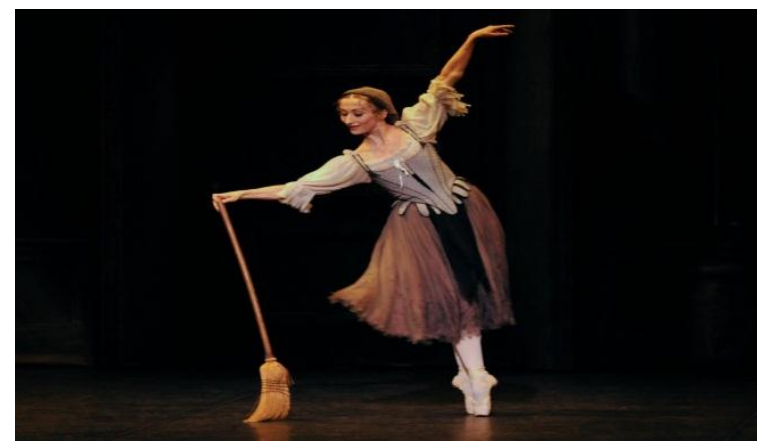

الفرقة الإنجليزية القومية للباليه : باليه سندرييلا بطلة العرض داريا كليمنتوفا Daria Klimentová ملابس سندريلالا بالو انها الباهته تعبر عن حالة الفقر التي تعيش فيه، ولكن لأنها ترقص بحركات واسعة تساعدها ملابسها حيث الخامة الخفيفة التي تبدو كالثيفون والتنورة الواسعة التي تشبه التتورة الرومانسية سالفة الذكر.

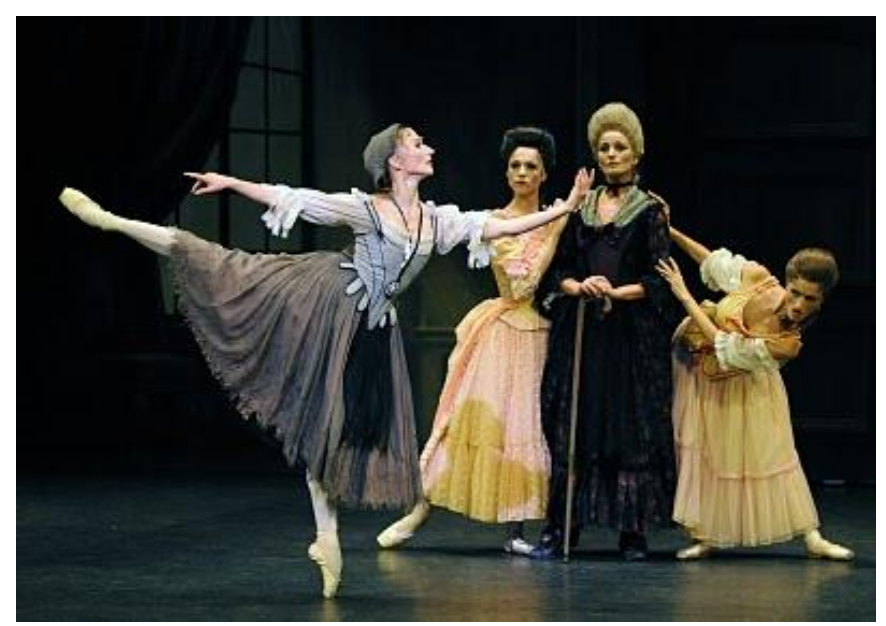

جين هاروت في دور زوجة الأب، و أبنتيها: أديلا راميريز، و إلي اليسار 
اللمانتومايه فيه مروض المباليه الكلاسيخيه

سارة مكللروي.(الفرقة القومية الإنجليزية للباليه).

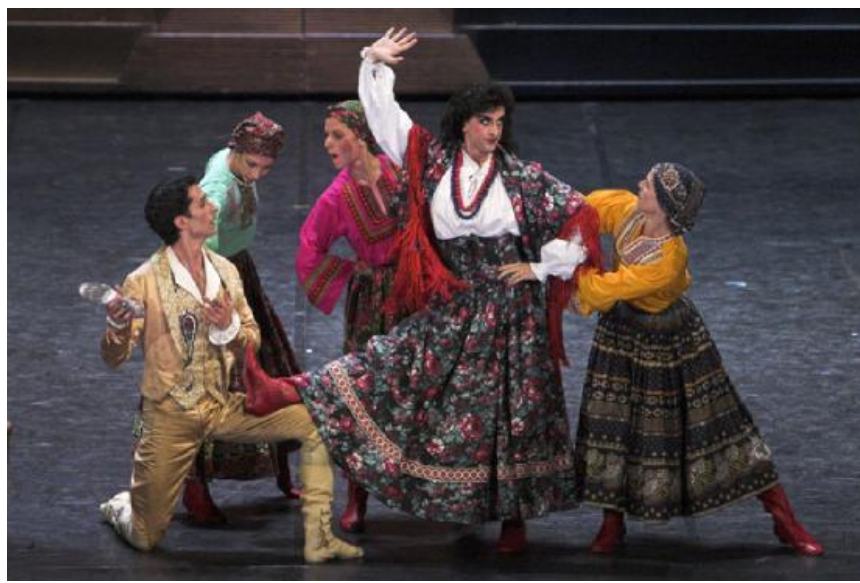

ولفريد روماني في دور زوجة الأب ، يقدم الدور بمهار ات تمثيلية

عالية أكثر منه راقص.. ونري الأحذية بالنسبة للأم والبنتين لا تتاسب الرقص الكلاسيكي حيث تمتاز بالكعوب العالية فأقي رقص ممكن بهذه

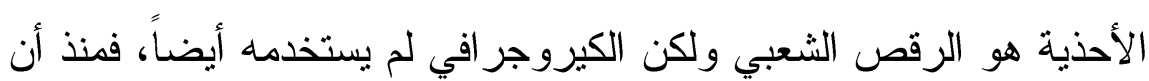

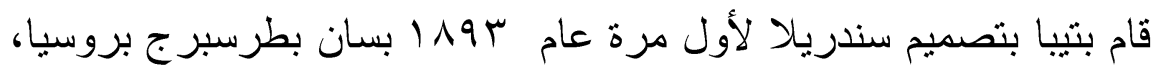
تتو الي الرؤي الإخراجية الكيروجر افية لدور الأم وفي كثير من الاحيان أدوار البنتين أيضاً بإختيار التمثيل الصامت كوسيلة للتعبير عن الأدوار و الثخصيات ، و أمتدث الإبداعات لتسكين الأدوار لر اقصين بدلاً من لإن راقصات، للتأكيد علي سمات الثخصيات الفظة و لإداخل نوع من الكوميديا الذي يتتاسب مع الثخصيات والمواقف الدرامية منل موقف الحذاء الذي لايتتاسب مع تلك الشخصيات لأنه (مقاس سندريلاد) وبالطبع يصاحب هذا الموقف التهافت من قبل الفتيات وحتي الأم علي أن يجربن 
اللمانتومايه فيه مروض المباليه الكلاسيخيه

الحذاء وما يصحب ذلم من صر اع أو تعبيرات إيماعية عن الغضب من الأخريات

أو الحزن لعدم مناسبة الحذاء لقدمهن. هذه اللقطة من فيلم باليه سندريلال

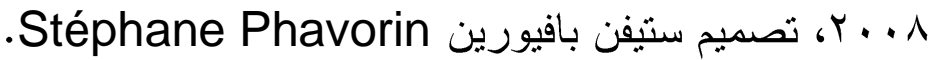

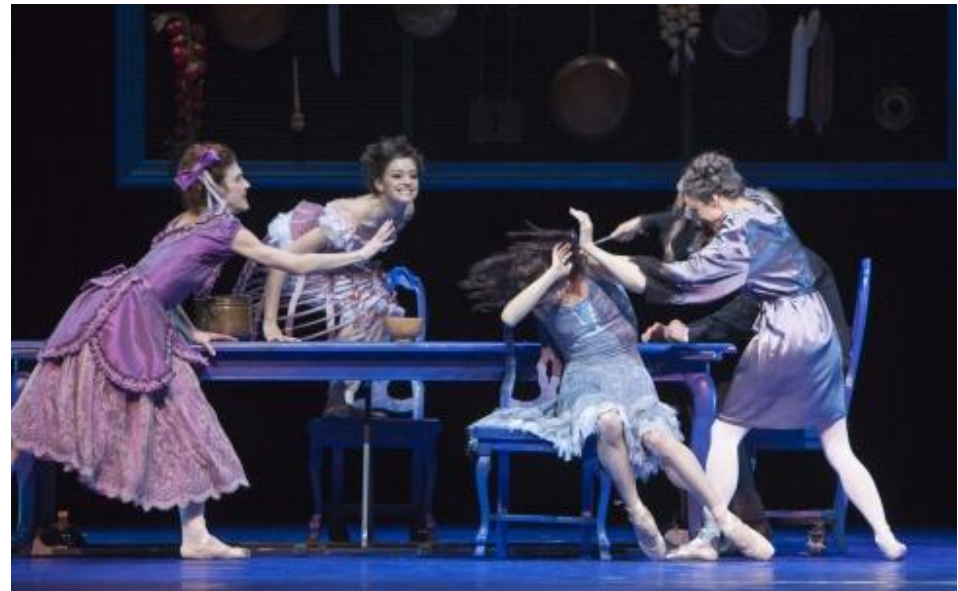

فرقة الباليه الألمانية: لحظات تمثيلية صامتة : زوجة الأب ثقص شعرسندريلا و وفرحة إبنتيها، ونلاحظ ملابس الأم الضيقة التي لا تتيح للممثلة/الراقصة أداء حركات راقصة متتوعة بينما ملابس البنتين وسندريلا تبدو عكس ذللك لتتيح لهن القيام بالحركات التي تم تصميمها ... مع ملاحظة أنه في معظم عروض باليه سندريلا بتفق الكيروجر افيين

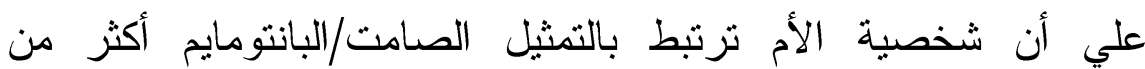

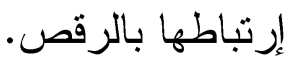




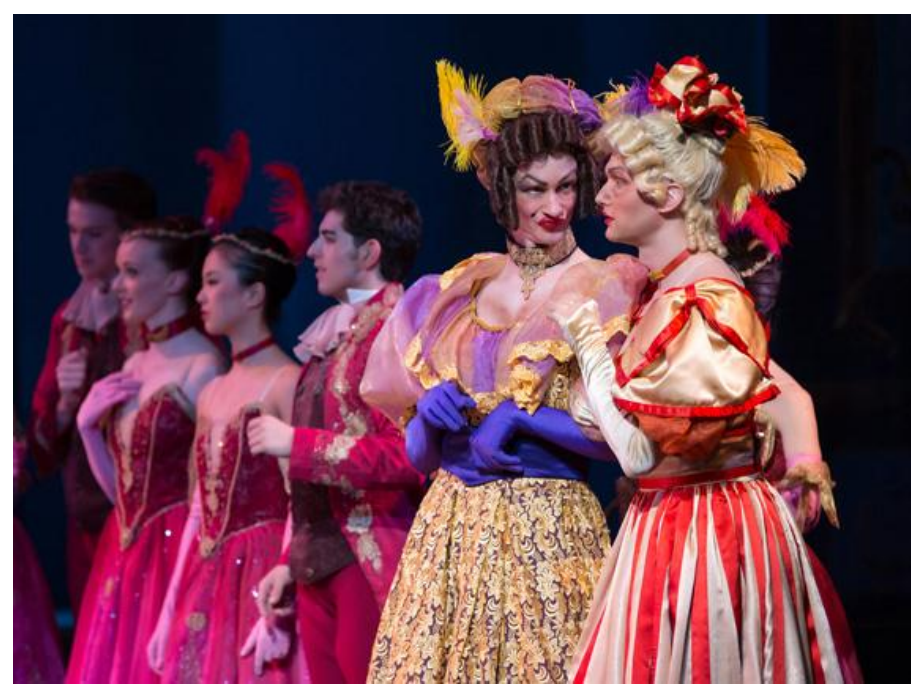

عرض سندريللا. لفرقة كولورادو للباليه: يقوم بأدار أدوار الأختين غير الشقيقتين لسندريلاخ كل من: كيفين ويلسون و جيسي ماركس. رؤية الكيروجرافي تتطابق مع رؤية آشثون مصمم باليه سندريلاد لفرقة ميتزوبوليتان أوبرا هاوس - نيويورك ... ع. . . حيث يقوم بدوري الأختين كل من روبرت هيلمان، وأنتوني دويل بالتبادل مع آشتون مصمم العرض ومخرجه الذي أضاف سمات ذكورية متجملة للأختين مبالغة في إظهار هما بصورة قوية بدنية تتمحي منها الأنوثة رغم تظاهر هما بها، ويبتعدا عن تللك الرقة التي تتسم بها السندريلاد. بالإضافة إلي الطابع الكوميدي الذي تتسم به الثخصيات والتي يضيف إليها الممثلين (الذكور) بالملابس التي تذكرنا بمهرجي البلاط الملكي في عصر النهضة وممثلي الكوميديا دي لازتي. 
اللمانتومايه فين مروض المباليه الكلاسيخيه
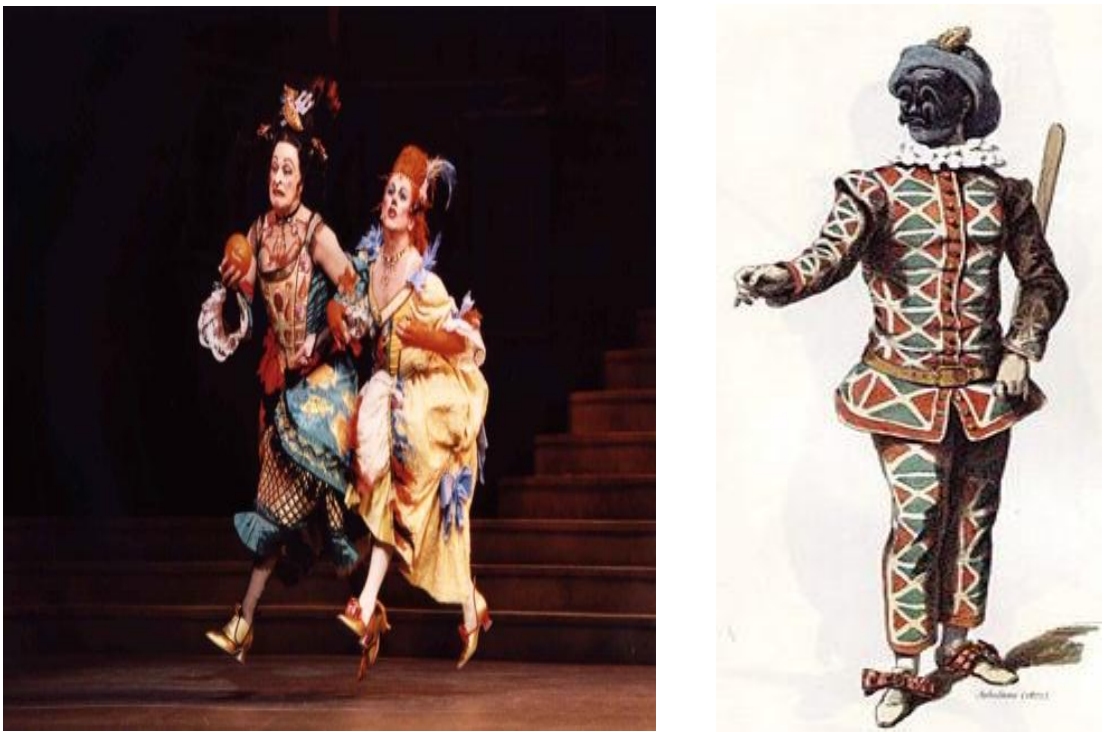

هاريكان أحد الثخصيات باليه سندريلا لفرقة ميتروبوليتان أوبرا

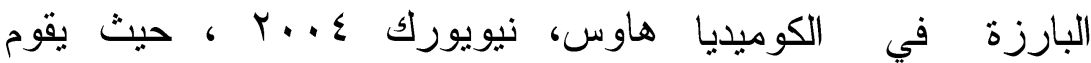
بدوري الأختين كل من روبرت هيلمان، ديالزرتي وأنتوني دويل. نلاحظ التشابه في المظهر

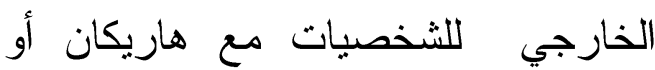
هاريكوين بالصورة المقابلة

\section{r r بالبه دون كيشوت Don Quichatte}

قصة وتصميم: بيتيبا، موسيقي: لودفيك مينيكوس، أول عرض بموسكو علي مسرح البولشوي من ع (1-7r ديسمبر 971 ام. وهذا العرض عينة التحليل قدمته فرقة مسرح مارينيسكي عامج؟...، عن قصة 
اللمانتومايه فيه مروض المباليه الكلاسيخيه

سيربانتيس، وإعداد درامي ماريسوس بتيبا، الكيروجرافي: الكسندر جورسكي ( مع الإحتفاظ لأسلوب بتيبا عن إخر اجه لأول دره) يعتمد التعبير الدرامي لكل من دون كيشوت وتابعه سانشو علي التمثيل الصامت؛ فالأول عجوز حالم بالبطولة، والآخر بدين لا يستطيع

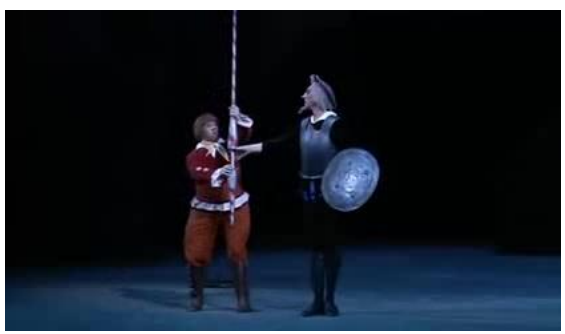
الرقص منل الر اقصين الآخرين. دون كيشوت العجوز وتابعه دون كيشوت في المشهد الإفتتاحي سانشو كلاهما لا يستطيعان الذي يبرز معالم الثخصية الجامحة الرقص الأول عجوز و الثاني بدين إلي بطو لات لا تستطيع تحقيقها.
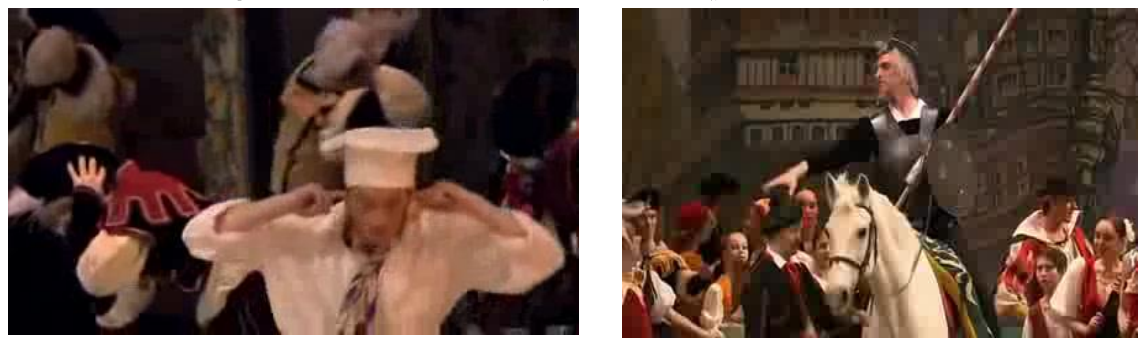

دخول دون كيشوت إلي المدينة الطاهي في المدينة يسد أذنيه تعبيراً علي حصان يؤكد الشكل التمثيلي عن عدم رغبته في أن يسمع ما يقال الكسي 
الملانتوهايه هين كروض المباليه الكلاسيحيه
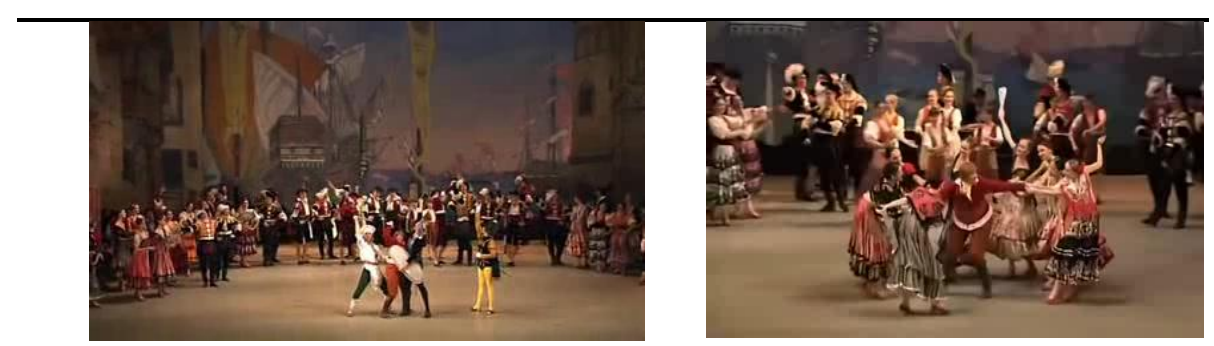

سانشو يرقص مع الفتيات اللائي دون كيشوت، سانشو، الطاهي؛ ثلاث يمرجنه ويتجاذبنه في حركات شخصيات إعتمدن علي البانتومايم في الاداء. مسرحية تعبيرية بسيطة .

\section{r. بالبه روميو وجوليث}

أحداث هذا الباليه مأخوذه من مسرحية شيكسبير الشهيرة روميو

وجوليت، التي كتبها عن أسطورة شعبية إيطالية وقعت في عامب. سام. أعدها للبايه ليونبد لافروسكي، كيروجرافي: سرجي بروكوفيف. عرضت

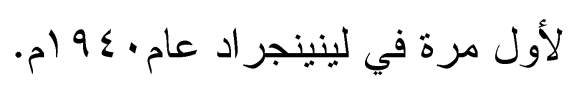

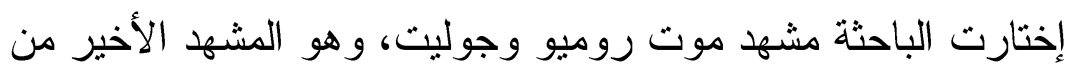

هذا الباليه لتستتد إليه فيما توصلث إليه بأن طبيعة الموقف الدرامي نوجه الكيروجر افي إلي وسيلة التعبير، وهي في هذه الحالة البانتومايم/التعبير الصامت. وتعرض الباحثة لقطات من المشه الأخير من باليه روميو وجوليت(المشهد: يدور داخل مقبرة جوليت) حيث يصل روميو عندما يعلم بموت جوليت ويجاول في هذا المشها يرقص معها جاهداً. يحملها تارة وتسقط منه ثم يرفعها من جديد. يحتل البانتومايم هذا المشهد كتعبير درامي عن الموقف حيث تبدو جوليث جثة هامدة لا تستطيع الحركة والحزن المسيطر علي روميو الذي يقرر الإنتحار ليموت إلي جوار حبيبته. لكن 


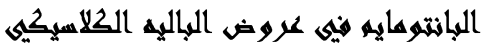

جوليت التي أخذت دواء كي يظهر علي جسدها علامات الموت إستبقت متأخراً لتجد حبيبها يرقد ميتاً، فتفزع وتقرر بسرعة أن نتحر بالخنجر، ثماء ترقد مرة أخري و ولكنها النهاية، كان التعبير تمثيلياً في حركات و إنفعالات يمكن أن تؤديها ممثلة /غير راقصة في نفس المشهذ إذا ماكانت روميو وجوليت عرضاً تمثيلياً صامناً.
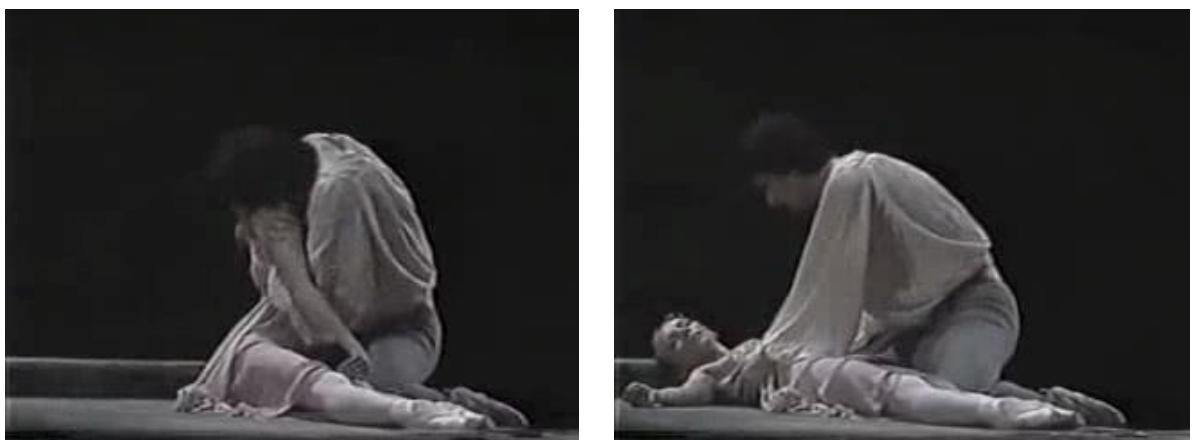

r

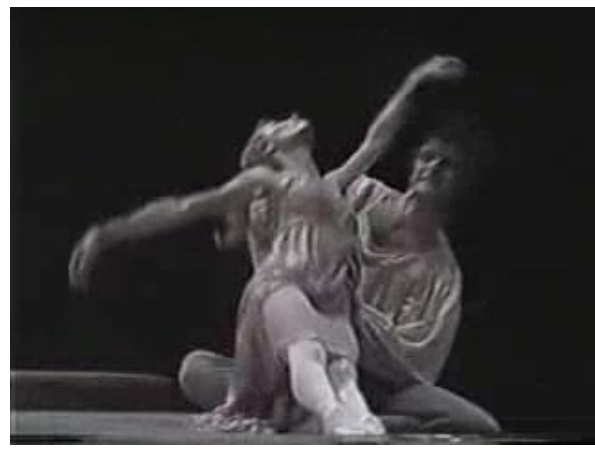

$\varepsilon$
1

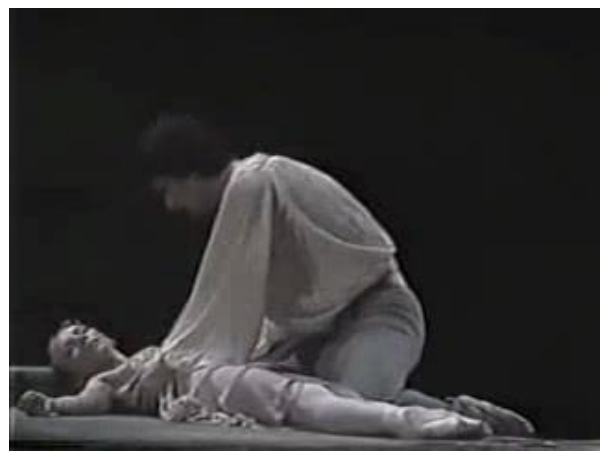

r 
المبانتوهايه فينى مروض المباليه الحلاسيكيه
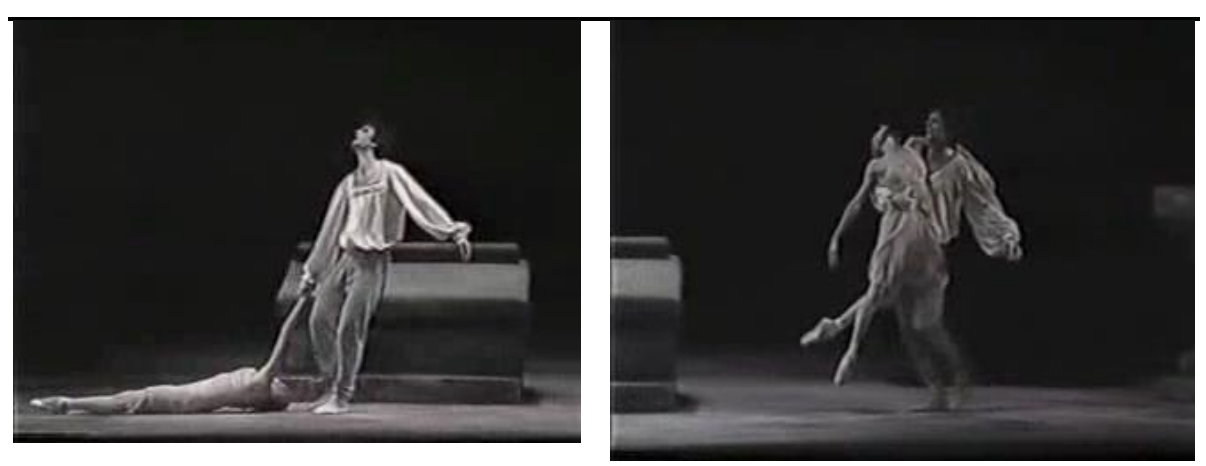

7

0

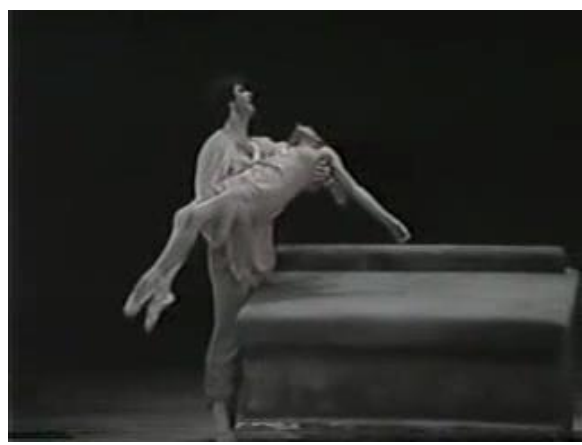

$\wedge$
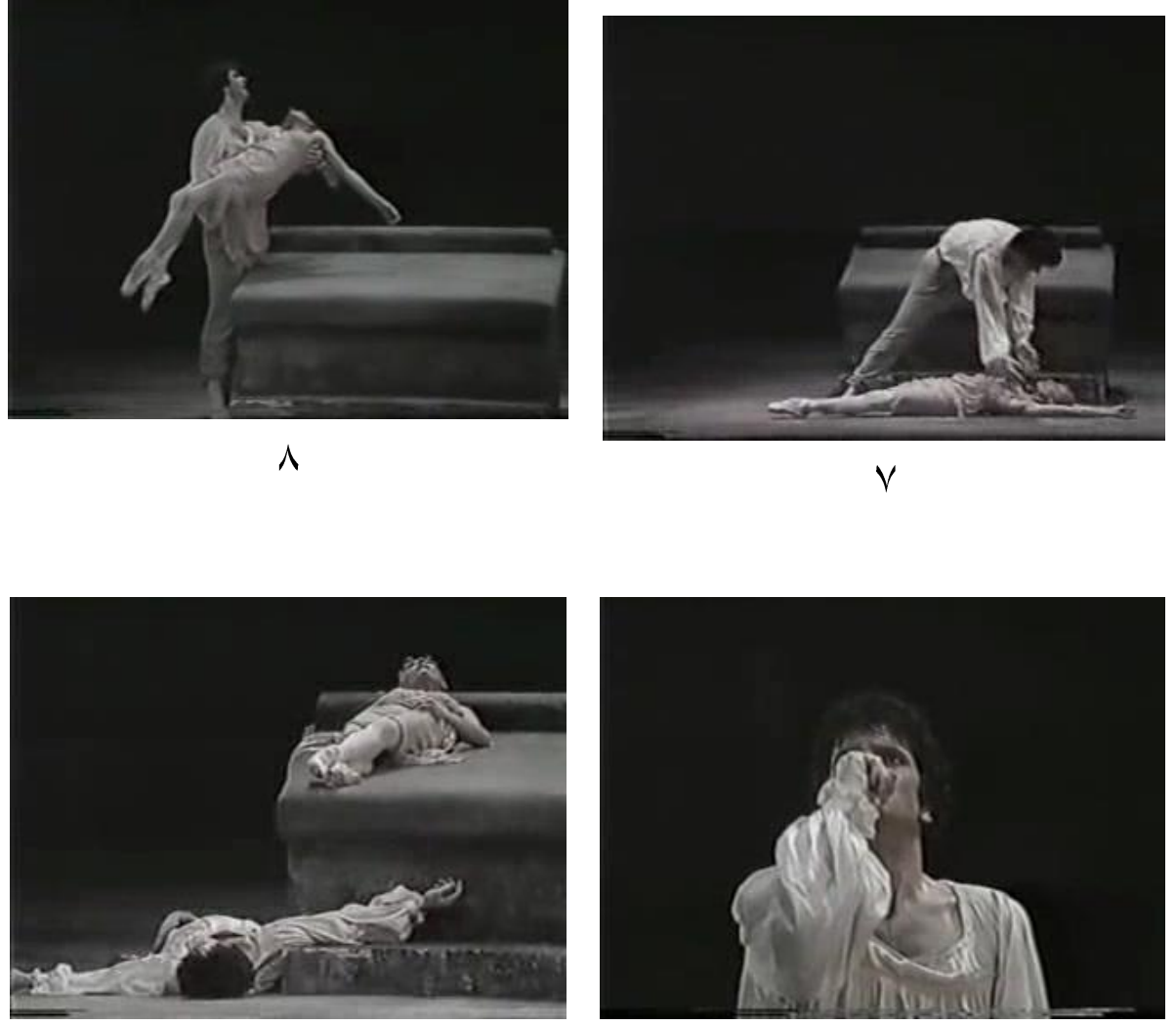

1

9 
المبانتوهايه هيى مروض المباليه الكلاسيخيى

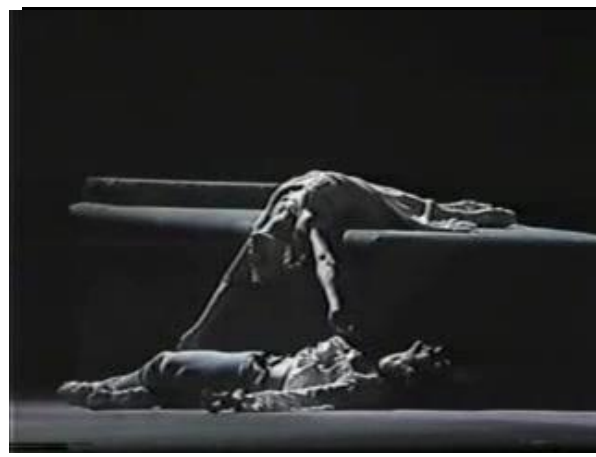

IY

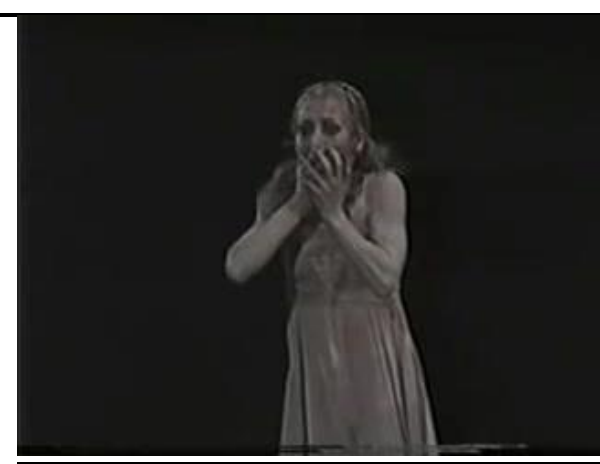

11

The Fountin of بالبه نافورة باخشاساراي(قصر المنتزة)

\section{Bakhchisaray}

القصة هي معالجة لأحدي قصائد الثاعر الروسي بوشكين بواسطة ن. د. فولكوف، عن شخصية الخان جيري الذي بندي نافورة في مقصورة

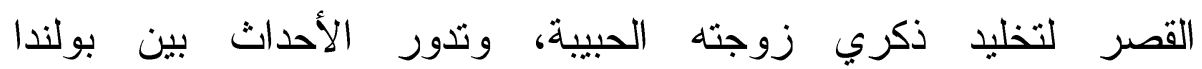
وباخشاسار اي أثناء هجوم التتار علي تلك البلدة.

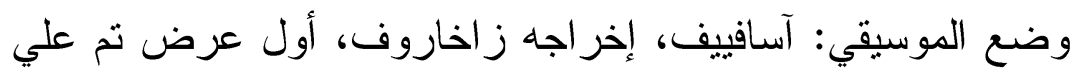
مسرح البولثوي بموسكو في اليونيه بسو ام. تعتمد الثخصية الرئيسية زئية

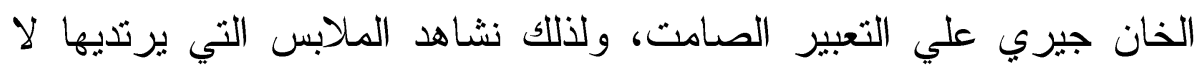
تساعد علي الرقص فهو يرتدي سروال/بنطلون واسع ومحكم من عند

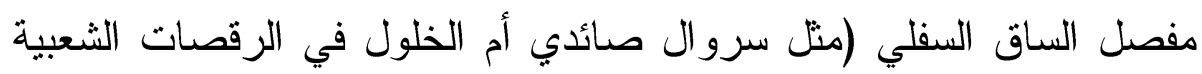

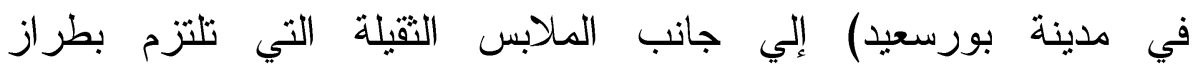

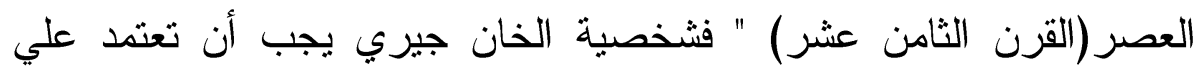
التمثيل الإيمائي، ولا تتطلب أداء أي حركة راقصة، ولكن يجب انب ان يكون 
المبانتمهايه هينى لمروض المباليه الكلاسيحيى

ممثلاً مدتاز اً بؤدي مشاهد التمثيل الإيمائي بكل دقة ويجسد من خلال تعبير ات وجهه".
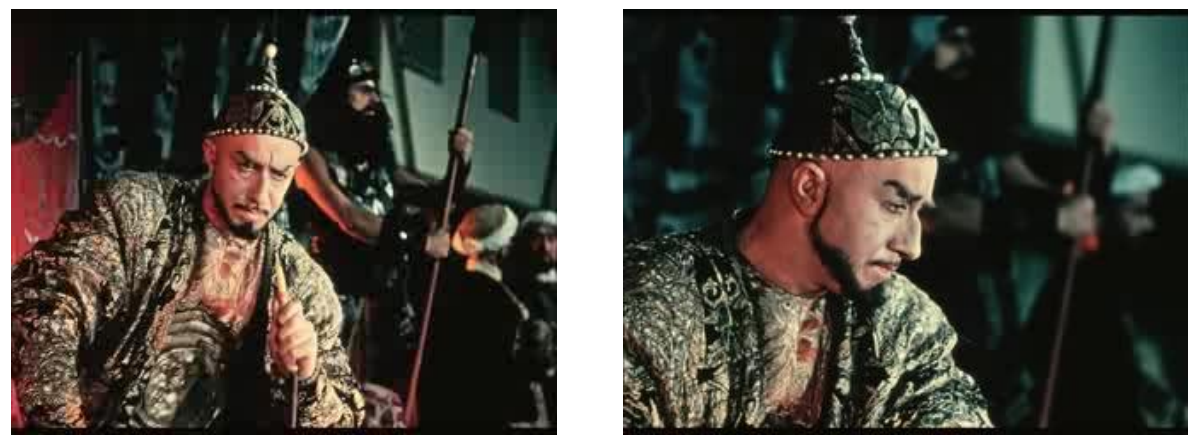

الخان بيزي بجلس مهموم بفكر التفكير العميق الذي بسطر علي فكر ويستمر هذا التعبير قبالة الــ ا دقائق الخان جيري وهو بشرب النرجيلة (الثيشـة) غير مكترث بأحد
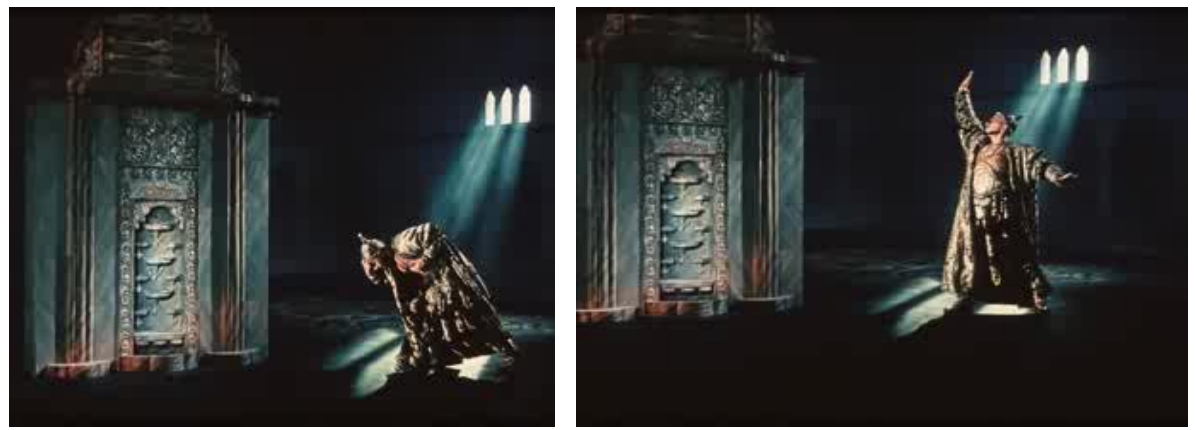

حركات تعبيرية تصور حزن الخان الخان جيري منحنياً أمام النافورة جيري علي زوجته المحببه ماري التي تعبيزاً عن الحون والأسي لفقدان بني من أجلها هذه النافورة الجميلة . زوجته. 


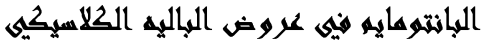
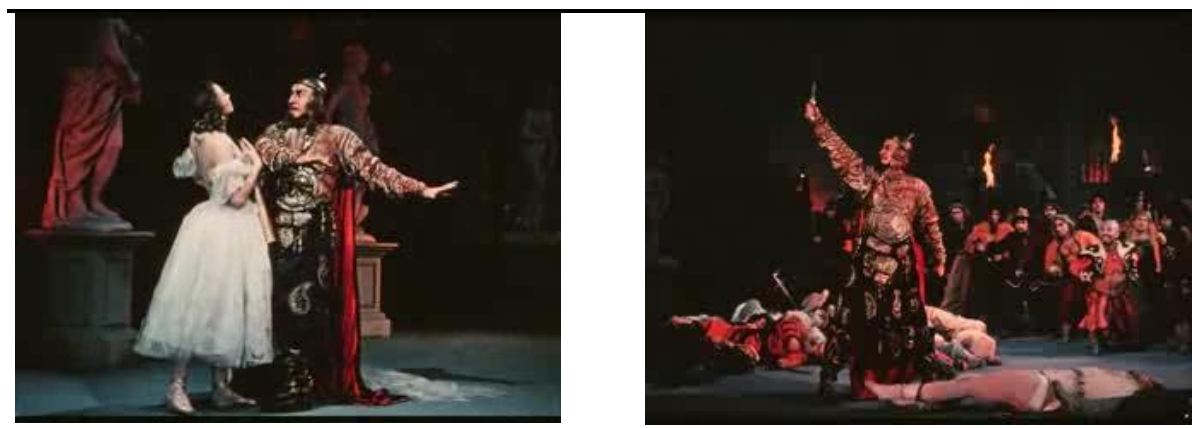

الخان جيري لحظة قتل فاستلاف الأزياء المسرحية المتكاملة والتي

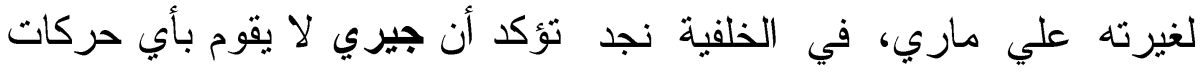

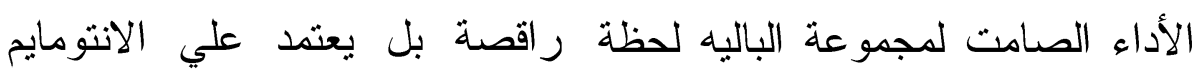

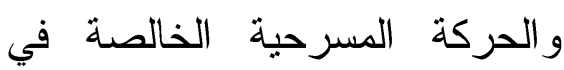

التعبيز
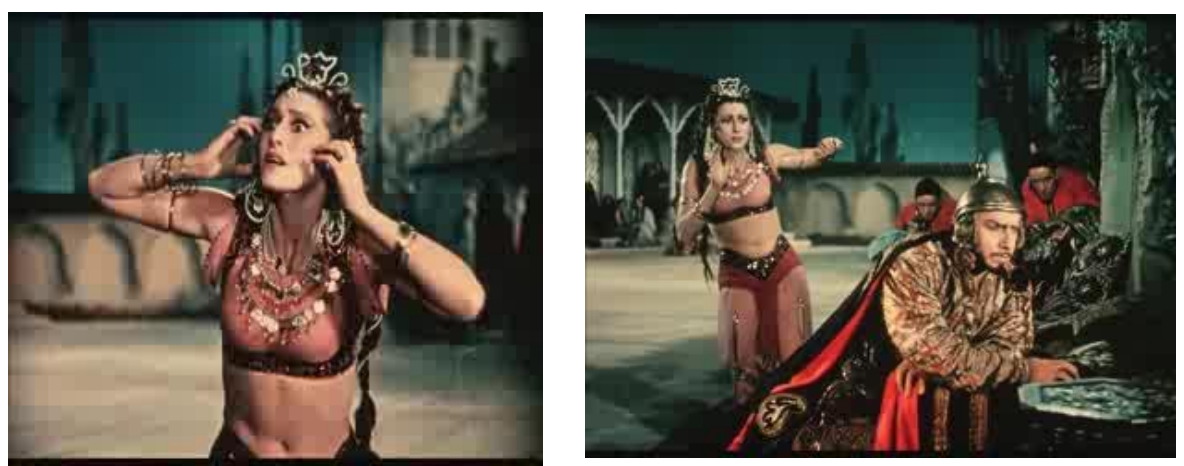

هذا العرض لفرقة باليه روسية عام شخصية زاريما (إحدي زوجات جيري) في لحظة تعبيرية صامتة

تؤكد هلعها لعزوف جيري عنها

• عرض البالبه الكومبِي لفرقة بالبه فينتا 


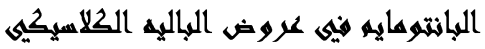

يعتد هذا العرض القصير الذي تشارك فيه ب راقصات بمصاحبة عازف البيانو الذي يجلس علي خشبة المسرح( وكأنهن في بروفة)علي أخطاء متتالية تقع فيها الراقصات علي التوالي وتثوم أحدهن بالتتبيه للخطأ إما بالإثارة أو بالحركة المسرحية الصامتة أوبالإيماءة (تعبيرات الوجه لونه فقط).
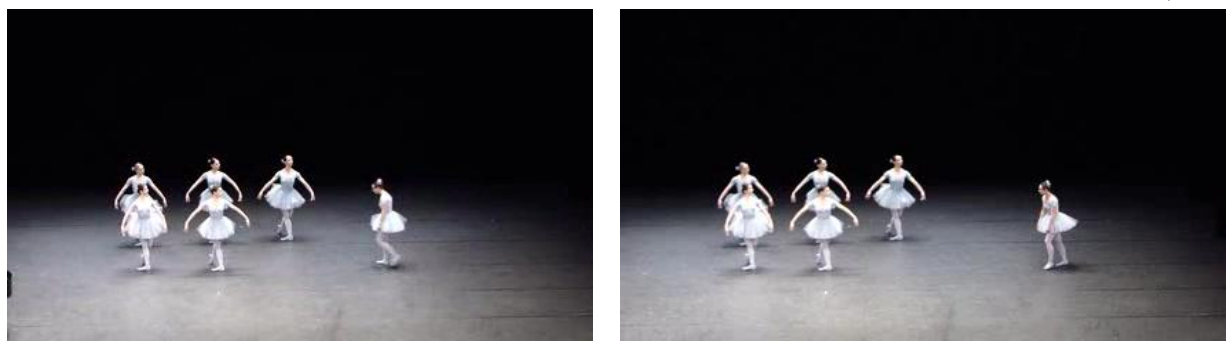

في بداية العرض تتاخر احدي تذهب الراقصة المتأخرة بمشية تعبر الر اقصات التي ترندي نظارة وينظرن عن الأسف وهي مطاطاة الرأس.

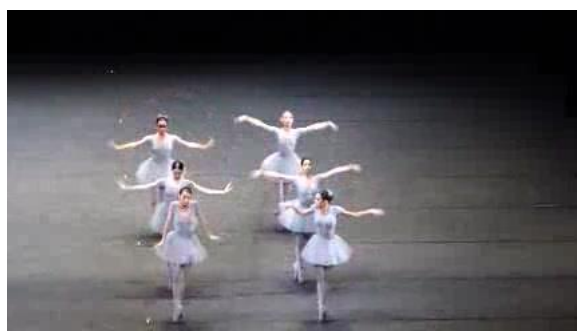
إليها لكي تتضم إليهن.

فجاة تكتشف الفتاتان (اللتان في تعبر كلتا الفتاتان بالإثارة باليدين

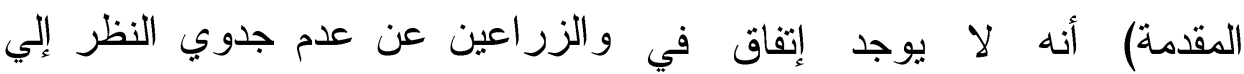

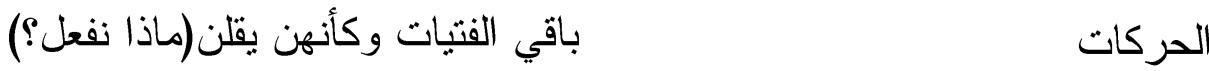




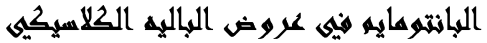
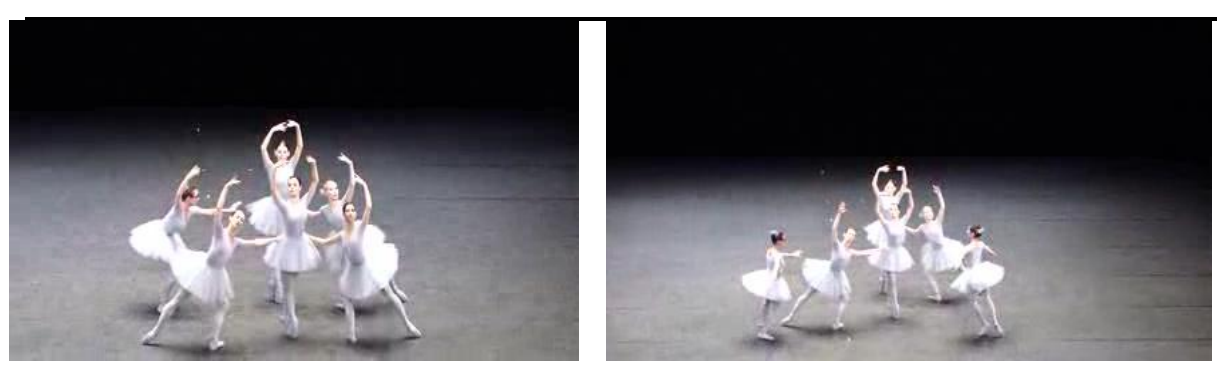

تبدو الفتاة (ذات النظارة) في موضع تحاول أن تعدل من حركتها وتاخذ خاطيء في التثكيل الحركي فتتسمر مكانها المفترض حسب تصميم الرقصة ولكن بشكل تعبيري كوميدي.
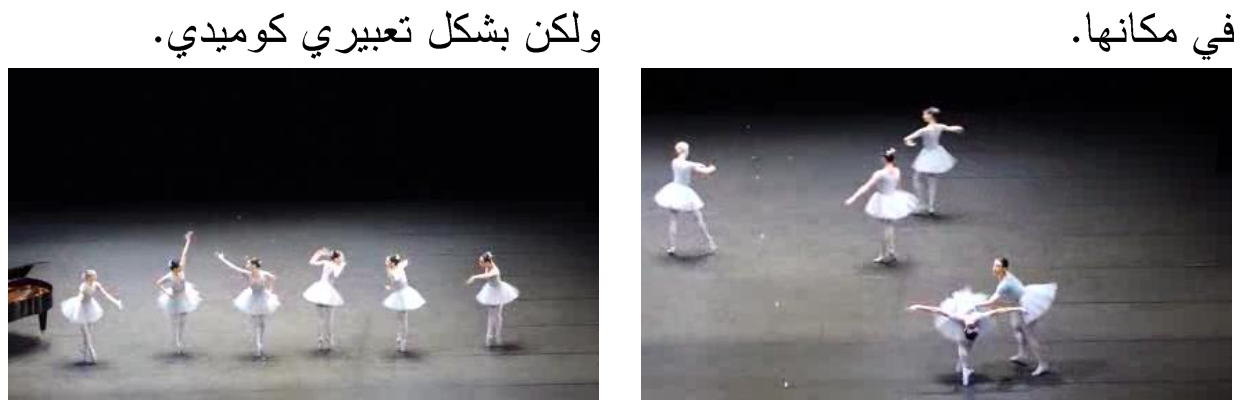

الإثشارات المعبرة عن الإضطراب في

إحدي الر اقصات تتبه الر اقصة الأخري

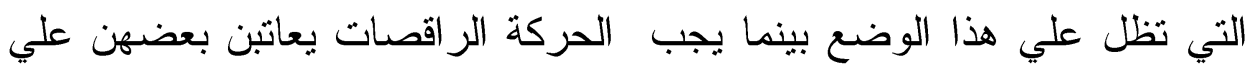

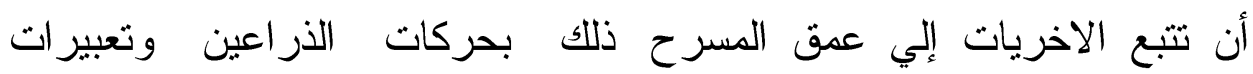
لعمل التشكيل التالي لكنها مستغرقة الوجه، وكل واحدة بطريقة مختلفة. ونتابتة وكانها نائمة في هذا الوضع.

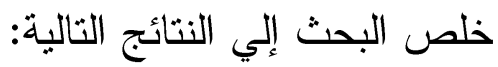


ا. إن العلاقة بين الرقص التمثيل الصامت ممثدة، وأن إيطاليا موطن الباليه كانت أيضاً موطناً لفن البانتومايم الذي يعد الجد الأصيل لفن الباليه منذ

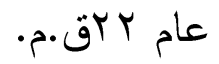
Y. بدأ الإهتمام بالتمثيل الصامت/البانتوميم في مجال الرقص و الباليه علي يد جان جورج نوفير الذي تأثز بالممثل الإنجليزي ديفيد جاريك وأسلوبه في التمثيل في بدايات النصف الثاني من القرن الثامن عشر . r. من خلال دراسة وتحليل عينة البحث وجدت الباحثة أن الكيروجر افي يلجأ إلي التمثيل الصامت/البانتومايم كوسيلة للتعبير في الحالات الأتية: أ- طبيعة الموقف الدرامي: بعض المواقف الدرامية تبدو غاية في

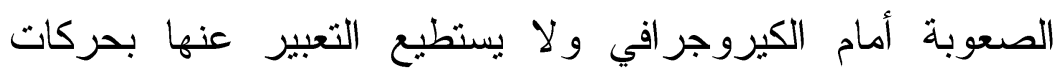
الرقص لذا يلجأ إلي التمثل الصامت والإيماءة كوسيلة للتعبير عن الموقف مثل مشهد موت روميو وجوليت. ب- طبيعية الشخصية الدر امية: يرتبط البانتومايم بالشخصية الكوميدية، أو بالسياق الكوميدي عامة، كما في العرض الكوميدي لفرقة باليه فيننا. أما الثخصيات التراجيدية فحسب رؤية الكيروجر افي، فمثلاً في باليه باخشاسار اي إختار الكيروجر افي التعبير الصامت طوال

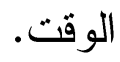

ت- الأبعاد المادية للشخصية: إذا كانت الشخصية الدرامية التي يقدمها الر اقص- بفرض أنه يُمثلها باللغة الراقصة- بدينة لا تستطيع

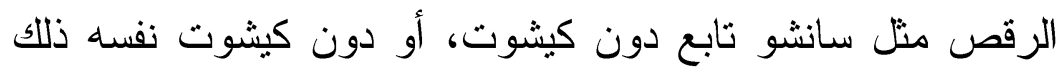


اللمانتومايه هيه مروض المباليه الحلاسيخيه

العجوز الذي لا يساعده عمره علي الرقص، فيختار له الكيروجر افي حركات مسرحية ويصمح حركات تعبيرية صامته نتناسب مع عُمر الثخصية وما تستطيع أن تؤديه بشكل يمكننا رؤيته في أي مسرحية و اقعية غير راقصة. 


\section{الحو اشي}

' كان مؤدي البانتومايم - قديماً - يتبع نظام غذائي كما يفعل الطلبة و الطالبات في معاهد الباليه ومدارسه للمحافظة علي الرشاقة و اللياقة البدنية ولكي يتمكن من أداء الحركات والرقصات المختلفة. كما كان يتدرب كثيرا ليكنسب مهارات مختلفة تمكنه من أداء الثخصيات

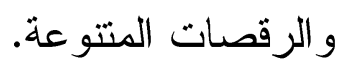
' أنظر، باري رولف(تحرير): كتابات في فن التمثيل الصامت"مقالات لأشهر فناني المايم"، ترجمة د.سامي صلاح، القاهرة، وزارة التقافة، إصدارات

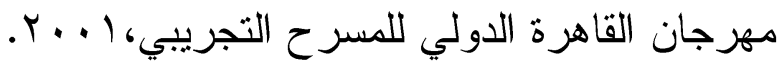

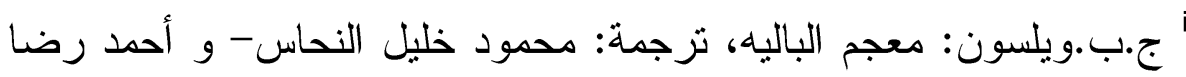
محمد رضا، القاهرة، دار الكتاب للطباعة و النشر ،د/ت. ' أنظر، جاك لوكوك، جان جبريل كاراسو، وجان كلود لالياس: المنظومة الثاعرية لجسد الممثل، ترجمة د. سهير الجمل، القاهرة، وزارة الثقافة،

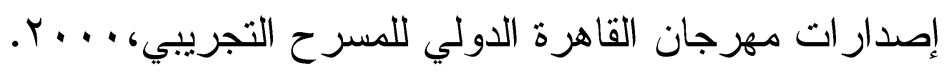

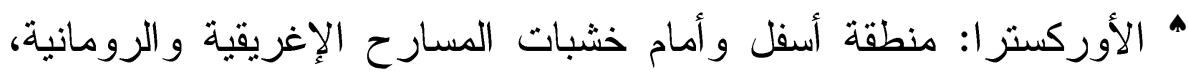

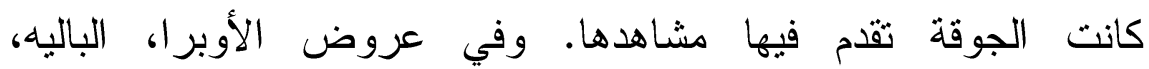
و الدسرحيات الموسيقية - في العصور الحديثة - تجلس فيها الفرقة الموسيقية وهم مجموعة العازفين الذين يقومون بعزف المقطوعات

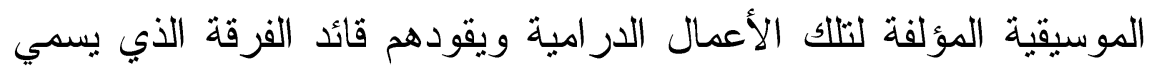


مايسترو. وتسمي الفرق الموسيقية بالأوركسترا السيمفوني نسبة لهذا المكان.

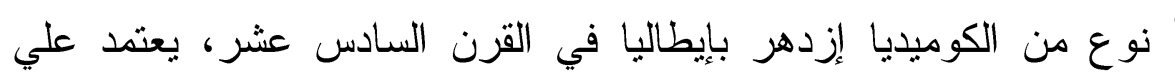

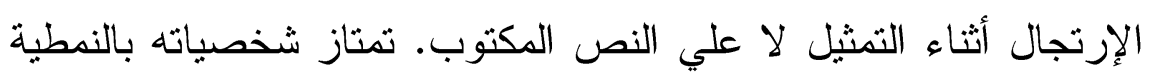

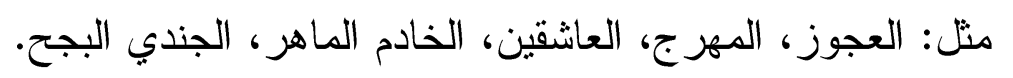

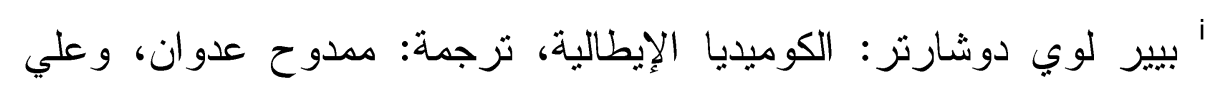

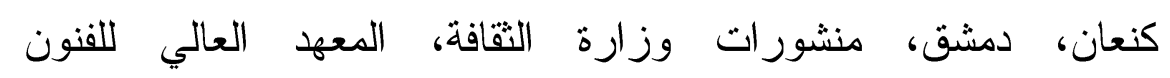

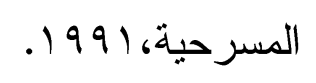

'أيفان أحمد عباس: تتوع الفنون وارتباطها وتأثثرها علي فن الرقص،

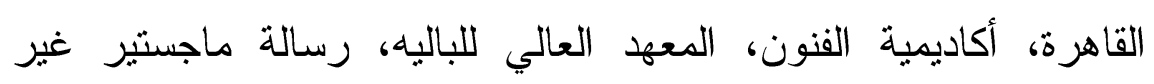

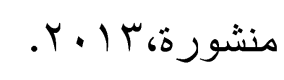

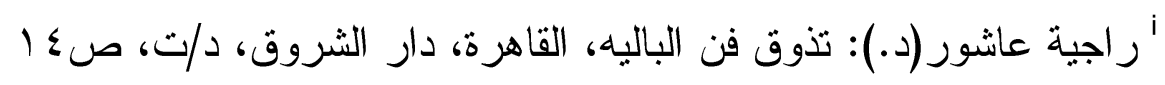

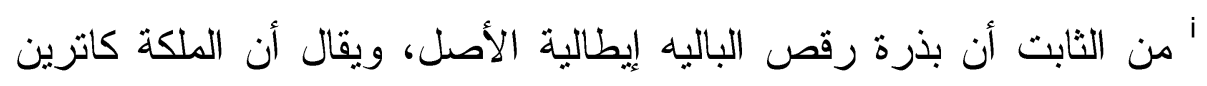

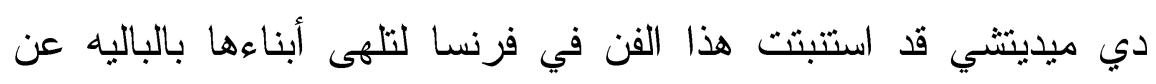
السياسة التي كانت شغلها الشاغل.

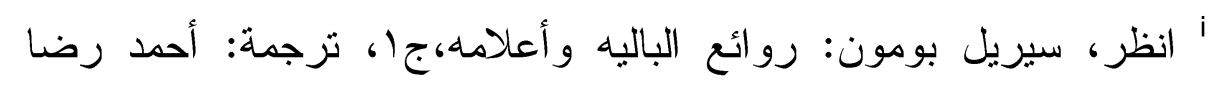

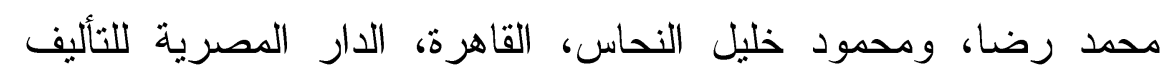

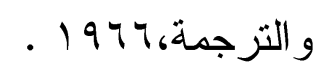

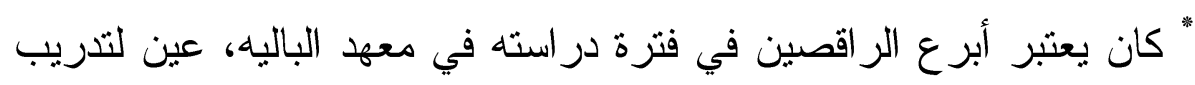

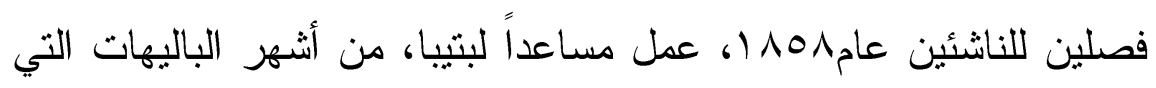
أخرجها: كسارة البندق، سيليفا، هارليم، الغابة المسحرة، جمال أثبيلية. 
' أنظر، أحمد حسن جمعة(د.): الدراما الحركية وفن الباليه، جا، القاهرة،

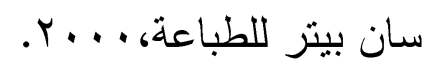

.Cheristout M.F: Le Ballet de cour et Louis ,xiv ${ }^{i}$ 'أوديت أصلان: فن المسرح، جrا، ترجمة: د.سامية أسعد، القاهرة، مؤسسة

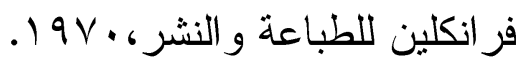

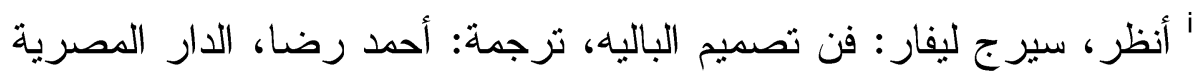

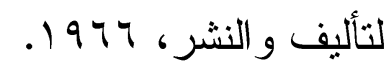

* بدأت الجماهير ومديرو المسارح في ملاحظة جاريك عندما قام بتمثيل

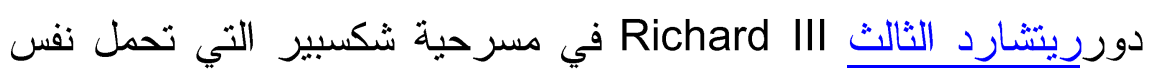

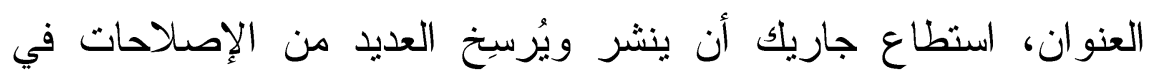

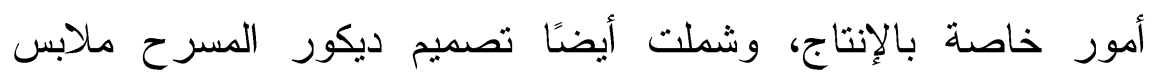
الممثلين وحتى المؤثرات الخاصة، كما سعى جاريك لتقويم سلوكيات

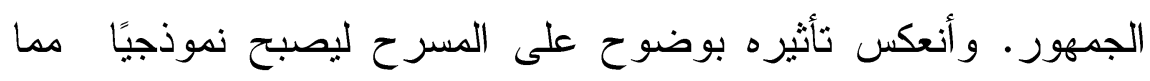

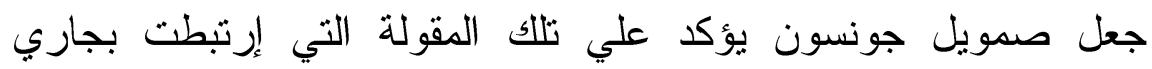

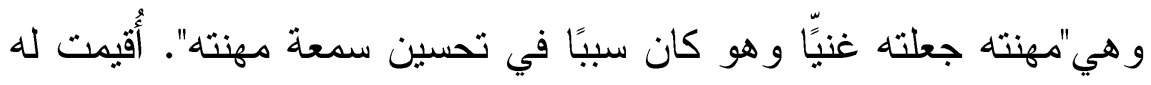

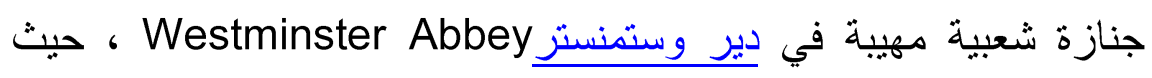

دوفْن في ركن الشُعر اء Poets' Corner

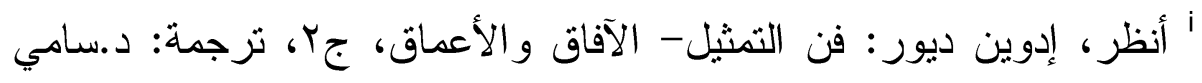

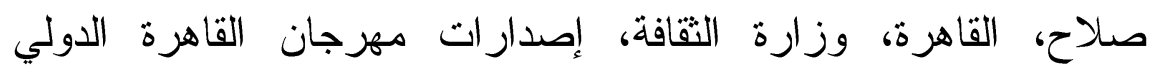

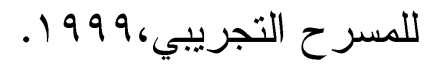


اللمانتومايه هيه مروض المباليه الحلاسيخيه

'أنظر ، إيفيت نجيب الببلاوي: الشخصية الكوميدية و التر اجيدية وتجسيدها في الباليه الكلاسيكي، القاهرة، أكاديمية الفنون، المعهد العالي للباليه، رسالة

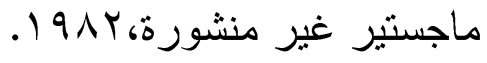

